\title{
Pharmacogenomics and Pharmacogenetics in Osteosarcoma: Translational Studies and Clinical Impact
}

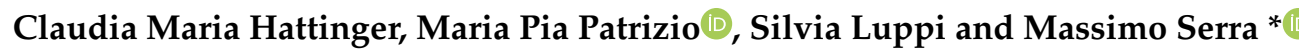 \\ IRCCS Istituto Ortopedico Rizzoli, Laboratory of Experimental Oncology, Pharmacogenomics and \\ Pharmacogenetics Research Unit, 40136 Bologna, Italy; claudia.hattinger@ior.it (C.M.H.); \\ mariapia.patrizio@ior.it (M.P.P.); silvia.luppi@ior.it (S.L.) \\ * Correspondence: massimo.serra@ior.it
}

Received: 28 May 2020; Accepted: 25 June 2020; Published: 30 June 2020

check for updates

\begin{abstract}
High-grade osteosarcoma (HGOS) is a very aggressive bone tumor which primarily affects adolescents and young adults. Although not advanced as is the case for other cancers, pharmacogenetic and pharmacogenomic studies applied to HGOS have been providing hope for an improved understanding of the biology and the identification of genetic biomarkers, which may impact on clinical care management. Recent developments of pharmacogenetics and pharmacogenomics in HGOS are expected to: i) highlight genetic events that trigger oncogenesis or which may act as drivers of disease; ii) validate research models that best predict clinical behavior; and iii) indicate genetic biomarkers associated with clinical outcome (in terms of treatment response, survival probability and susceptibility to chemotherapy-related toxicities). The generated body of information may be translated to clinical settings, in order to improve both effectiveness and safety of conventional chemotherapy trials as well as to indicate new tailored treatment strategies. Here, we review and summarize the current scientific evidence for each of the aforementioned issues in view of possible clinical applications.
\end{abstract}

Keywords: osteosarcoma; pharmacogenomics; pharmacogenetics; toxicity; tailored treatment

\section{Introduction}

Osteosarcoma, the most common tumor of the bone, is a very aggressive malignant neoplasm that mainly arises in adolescents and young adults [1-3]. Different variants of this neoplasm have been described, of which the most common is the conventional high-grade osteosarcoma (HGOS) that affects patients younger than 40 years, is localized in the extremities and does not present evidence of metastasis at clinical onset [2]. Conventional HGOS is currently treated with surgical removal of the primary tumor and systemic pre- and postoperative multidrug chemotherapy protocols. This multimodal, aggressive treatment allows curing $60-65 \%$ of patients, but also exhibits a collateral risk for adverse toxicity events that cannot presently be predicted or efficiently prevented $[1,3-6]$. The drugs that are most commonly included in first-line HGOS chemotherapy are doxorubicin (adriamycin), cisplatin (cis-diamminedichloroplatinum), methotrexate and/or ifosfamide and/or etoposide $[3,5,7,8]$. In addition to these, there is a small group of drugs, which, although they do not exhibit the same efficacy of the aforementioned ones, are variably used in second-line and rescue chemotherapy protocols to treat relapsed HGOS patients $[3,4,7,9]$.

The ultimate goal of pharmacogenetics and pharmacogenomics (two terms that are frequently used interchangeably) is to define genomic variations, which may provide useful information to improve drug efficacy and reduce the risk of chemotherapy-related toxicities [10]. In the last decade, pharmacogenetic 
and pharmacogenomic approaches have been increasingly applied to the genetic characterization of HGOS and have started to yield insights which may be taken into consideration to modulate and, hopefully, improve the effectiveness and safety of currently used treatment protocols $[5,11]$. These studies are based on the application of genomic technologies to identify biomarkers related to drug efficacy or toxicity $[12,13]$.

The majority of studies, which have been performed so far in HGOS, have evaluated single nucleotide polymorphisms (SNPs) in several candidate genes of possible relevance for the biology, drug response, detoxification and susceptibility to treatment-related toxicities, in order to indicate biomarkers which may provide the bases for planning tailored treatments aimed to increase therapeutic benefits and limit adverse events.

In this review, we provide an overview of the most promising translational research findings of pharmacogenetics and pharmacogenomics in HGOS. In particular, we have focused on both pharmacogenetic (germline) and pharmacogenomic (tumor-associated, somatic) markers, which have been indicated to influence treatment response, survival and susceptibility to treatment-associated toxicities in HGOS patients, thus appearing as promising candidates for a translation to clinical practice.

\section{Germline Pharmacogenetic Markers Associated with Risk to Develop HGOS}

Biological risk factors for HGOS include tall stature, high birth-weight and therapeutic irradiation [14]. Rare cancer predisposition syndromes have been described to be associated with HGOS. They are not a common cause of HGOS, but the incidence of HGOS is higher in these patients compared to the general population (Table 1). It cannot be excluded that by using next-generation sequencing (NGS) approaches additional genes associated with inherited syndromes will still be discovered, as was shown in the Diamond-Blackfan anemia (DBA) families [15,16].

Table 1. Rare cancer predisposition syndromes associated with osteosarcoma.

\begin{tabular}{|c|c|c|c|c|}
\hline $\begin{array}{c}\text { Autosomal } \\
\text { Dominant } \\
\text { (Gene Involved) }\end{array}$ & $\begin{array}{c}\text { Incidence of } \\
\text { HGOS }\end{array}$ & $\begin{array}{l}\text { Estimated } \\
\text { Fold-Risk }\end{array}$ & $\begin{array}{c}\text { Autosomal } \\
\text { Recessive } \\
\text { (Gene Involved) }\end{array}$ & $\begin{array}{c}\text { Incidence of } \\
\text { HGOS }\end{array}$ \\
\hline $\begin{array}{c}\text { Li-Fraumeni } \\
\text { Syndrome (TP53) }\end{array}$ & $\begin{array}{c}3 \%[17] \\
5-11 \%[18]\end{array}$ & 107 [19] & $\begin{array}{l}\text { Rothmund-Thomson } \\
\text { Syndrome } \\
\text { (RECQL4) }\end{array}$ & $\begin{array}{l}32 \%[20] \\
48 \%[21]\end{array}$ \\
\hline $\begin{array}{c}\text { Hereditary } \\
\text { Retinoblastoma } \\
(R B 1)\end{array}$ & $12 \%$ [17] & $\begin{array}{c}200-400 *[22] \\
69-400 *[19]\end{array}$ & $\begin{array}{l}\text { Rapadilino } \\
\text { Syndrome } \\
(R E C Q L 4)\end{array}$ & $\begin{array}{l}13 \%[22] \\
40 \%[21]\end{array}$ \\
\hline \multirow[t]{2}{*}{$\begin{array}{l}\text { Diamond-Blackfan } \\
\text { anemia (genes } \\
\text { encoding } \\
\text { ribosomal proteins, } \\
\text { of which the most } \\
\text { common is RPS19, } \\
\text { and GATA1) }\end{array}$} & $\begin{array}{l}<1 \%[23] \\
14 \%[24]\end{array}$ & 42 [24] & $\begin{array}{l}\text { Bloom Syndrome } \\
\quad(\text { RECQL3) }\end{array}$ & $<12 \%$ [25] \\
\hline & & & $\begin{array}{c}\text { Werner Syndrome } \\
(\text { RECQL2) }\end{array}$ & $7 \%$ [22] \\
\hline
\end{tabular}

Footnote: estimated fold-risk values were available for autosomal dominant syndromes only. Legend: *after radiation therapy. Abbreviations: HGOS, high-grade osteosarcoma; TP53, tumor protein 53; RB1, retinoblastoma transcriptional corepressor 1; RPS19, ribosomal protein S19; GATA1, GATA binding protein 1; RECQL, RecQ like helicase.

The number of genes reported in the phenopedia database to be associated with HGOS has reached 170 [26] and will rise continuously. Although 117 genes have been reported in single studies and 35 in less than five, 18 genes have been reported more than ten times in association with osteosarcoma: excision repair cross-complementation group 1, 2 and 5 (ERCC1, ERCC2, ERCC5); X-ray repair cross 
complementing 3 (XRCC3); tumor protein 53 (TP53); mouse double minute 2 (MDM2); cytotoxic T-lymphocyte antigen-4 (CTLA-4); glutathione S-transferase P1 (GSTP1); methylenetetrahydrofolate reductase (MTHFR); ATP-binding cassette, subfamily B (MDR/TAP) member 1 (ABCB1); ATP-binding cassette, subfamily C (CFTR/MRP) member 2 (ABCC2); ATP-binding cassette, subfamily C (CFTR/MRP) member 2 ( $A B C C 3)$; glutathione S-transferase M1 (GSTM1); glutathione S-transferase T1 (GSTT1); cytochrome $\mathrm{C}$ oxidase subunit $8 \mathrm{~A}$ (COX8A); vascular endothelial growth factor $\mathrm{A}$ (VEGFA); tumor necrosis factor (TNF); transforming growth factor beta 1 (TGFB1). Many of them belong to DNA repair pathways or drug metabolism, transport and detoxification of the principal drugs used in HGOS chemotherapy.

\subsection{Common Genetic Variants}

Common genetic variants have been studied mainly by candidate-gene and pathway driven approaches applied to smaller cohorts and have revealed somehow contradictory results. However, these studies indicated at least 27 genes to be associated with risk for HGOS development [14]. A very comprehensive candidate gene approach, evaluating 4836 tag-SNPs of 255 candidate genes belonging to four pathways with possible biological importance for HGOS risk in 96 HGOS cases and 1426 controls identified 241 SNPs that were statistically significant $(p<0.05)$ [27]. However, after correction for multiple testing, none of these pathways remained significantly associated with HGOS risk confirming the complex biology of HGOS pathogenesis.

The first international genome-wide association study (GWAS) using a high-throughput approach including 941 samples and 3291 controls identified SNPs in the glutamate metabotropic receptor 4 (GRM4) gene and in a gene desert at chromosome 2p25.2 which were found to be associated with risk to develop HGOS [28]. The risk association between GRM4 rs11906953 and HGOS was subsequently confirmed in two studies carried out in Chinese populations [29,30].

A different approach was used by Yang and co-workers, who performed a gene-based GWAS analysis on a family-based trio data set including genotypes of 697,110 SNPs for 209 patients with HGOS and their unaffected biological parents [31]. Their objective was to identify height-related genetic markers associated with HGOS. They performed a Bayesian gene-based GWAS analysis in two steps. A total of 217 genes achieving genome-wide significance were identified. Ingenuity pathway analysis of this gene set indicated that genes were highly related to TP53, estrogen receptor signaling, xenobiotic metabolism signaling and RANK signaling in osteoclasts suggesting these pathways being associated with HGOS.

\subsection{Rare Genetic Variants}

Rare genetic variants have been studied in HGOS patients by targeted gene sequencing of TP53 [32] and in three pan-cancer cohorts including HGOS using whole-exome (WES) or whole-genome (WGS) sequencing [33-35]. The first, performing WGS or WES on 1120 pediatric cancer patients (39 HGOS), identified TP53, APC, breast related cancer antigen 2 (BRCA2), neurofibromin 1 (NF1), PMS1 homolog 2, mismatch repair system component (PMS2), RB transcriptional corepressor 1 (RB1) and RUNX family transcription factor 1 (RUNX1) to be affected by mutations in more than three cases [35]. The second, reporting WES data on germline DNA samples from 1162 prevalently adult sarcoma patients (124 HGOS) found that $55 \%$ of patients had an excess of pathogenic germline variants in the 72 pan-sarcoma genes, such as TP53, BRCA2, ataxia telangiectasia mutated (ATM), ataxia telangiectasia and Rad3 related (ATR), and ERCC2 [33]. The third, performed on 961 childhood cancer patients, suggested that $7-8 \%$ of the children carried an unambiguous predisposing germline variant [34].

Recently, the most comprehensive study reported WES and targeted sequencing data of germline DNA from 1244 patients with osteosarcoma in order to investigate the underlying germline genetic architecture [36]. Results were compared with 1062 in-house cancer free adult controls and 27,173 from the ExAC non-Finish European cancer-free resource. Analyses focused on 238 high interest cancer-susceptibility genes (114 cancer-predisposing genes, 14 genes associated with DBA, and 110 
cancer-associated genes previously described or reported in the catalogue of somatic mutations in cancer (COSMIC) with germline effects) followed by testing for mutational burden across 736 additional candidate genes ( 140 genes of the HuGE Phenopedia and 596 genes somatically altered in pediatric bone cancers or recurrent in any pediatric cancer based on COSMIC and annotation of published osteosarcoma somatic data). Variants were grouped in pathogenic (P) and likely pathogenic (LP) variants as in previous studies [32]. A significantly higher P/LP variant burden in the 238 high-interest cancer-susceptibility genes was found in the HGOS cases compared to the in-house controls restricted to European ancestry. A P/LP variant was identified in $28 \%$ of the cases, of which nearly three-quarters mapped to an autosomal dominant gene or a known osteosarcoma-associated cancer predisposition syndrome gene. Higher than expected frequencies of $\mathrm{P} / \mathrm{LP}$ variants were found in genes previously linked to osteosarcoma, e.g., cyclin dependent kinase inhibitor 2A (CDKN2A), menin 1 (MEN1), Von Hippel-Lindau (VHL) tumor suppressor, protection of telomeres 1 (POT1), APC, mutS homolog 2 (MSH2), ATRX chromatin remodeler (ATRX) and TP53.

\subsection{Meta-Analyses}

Several recent meta-analyses have been performed, including selected case-control studies, in order to obtain more robust results and to clarify the somehow contradictory results of individual small candidate gene and pathway driven studies.

The TP53 rs1042522 was studied in a meta-analysis including five publications with a total of 567 cases with bone tumors (HGOS and Ewing sarcoma) and 935 controls [37]. In the stratified group of patients with HGOS (527 patients and 807 controls) the GG genotype was significantly associated with risk for HGOS development vs GC/CC (odd ratio, $\mathrm{OR}=1.57$, confidence interval, $\mathrm{CI}=1.20-2.06$, $p=0.001$.

Polymorphisms of the GST family (GSTP1 rs1695, GSTT1 and GSTM1 null allele, and GSTM3 rs1799735 were analyzed in a meta-analysis including 24 case-control studies with a total of 2405 HGOS cases and 3293 controls [38]. All five genetic models were tested. Including all studies, the GSTT1 null genotype (OR $=1.2,95 \% \mathrm{CI} 1.02-1.52, P=0.031)$ and the GSTP1 (rs1695) variant allele (B vs A: $\mathrm{OR}=8.90,95 \%$ CI 2.72-29.20, $p<0.001$ ) were associated with higher risk for HGOS, whereas increased risk was also associated with the GSTT1 null genotype (OR $=1.30,95 \% \mathrm{CI} 1.03-1.64, p=0.025)$ but only in Asians and not in Caucasians.

The two most frequently studied variants of MDM2, rs1690916 and rs2279744, for which inconclusive data were reported regarding a possible association with risk to develop HGOS [39-41] were considered in a meta-analysis including six populations with a total of $246 \mathrm{HGOS}$ patients and 1760 controls (rs2279744) and 433 HGOS patients and 1959 controls (rs2279744) [42]. None of the two MDM2 SNPs was associated with risk to develop HGOS in any of the four models studied, suggesting that the role of MDM2 in the development of HGOS is less important than was previously expected.

A more comprehensive approach was used in a one meta-analysis considering 32 case-control studies with a total of 6924 HGOS patients and 8412 controls, and 24 SNPs in 14 genes [43]. Nine risk alleles (CTLA-4 rs231775; protein kinase CGMP-dependent 1, PRCKG rs454006; RecQ like helicase 5, RECQL5 rs820196; TNF- $a$ rs1800629; TP53 rs1042522; XRCC3 rs861539; VEGF rs699947 and VEGF rs3025039) with an average pooled $\mathrm{OR}=2.082$ (CI 1.59-3.26; $p<0.003$ ) and three protective alleles (interleukin 8, IL-8 rs4073; MDM2 rs1690916; and VEGF rs2010963) with OR $=0.61(0.51-0.72, p<0.038)$ were identified. However, the authors admit that one of the limitations of their study was that most of the studies included Chinese populations and therefore their data should be validated in different ethnic populations.

\section{Pharmacogenetic and Pharmacogenomic Markers Associated with Treatment Response and/or Survival}

Studies on genetic markers that may be associated with treatment response and outcome in HGOS have mainly focused on genes involved in tumorigenesis, DNA repair pathways, as well as 
in metabolism, transport, or detoxification of drugs used for conventional chemotherapy protocols. The most relevant studies and candidate biomarkers with a possible clinical impact which have been reported so far are summarized below and listed in Figure 1.
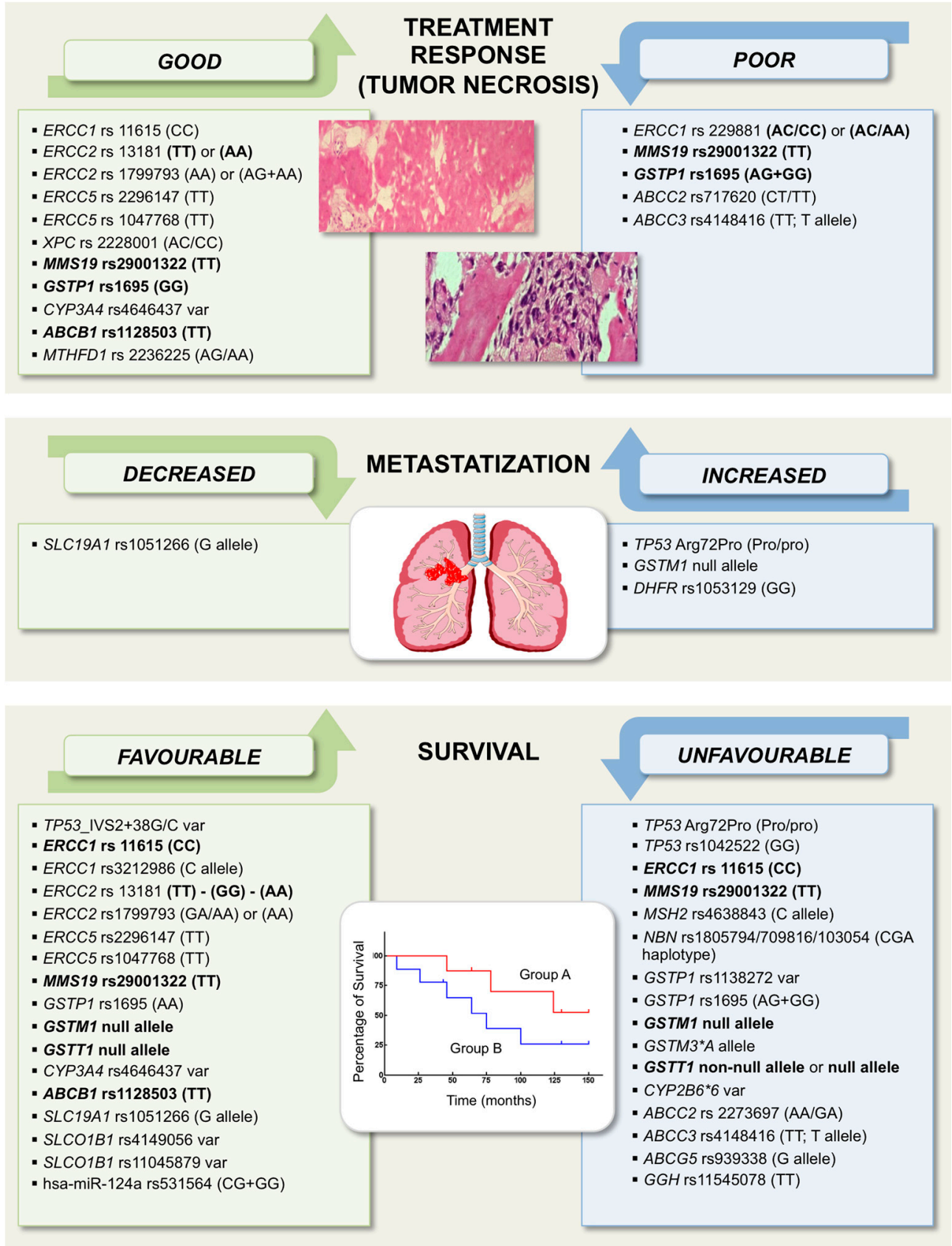

Figure 1. Pharmacogenetic and pharmacogenomic variations impacting on treatment response, outcome and prognosis in high-grade osteosarcoma (HGOS). Genes, polymorphisms and corresponding genotypes (inside parenthesis) are listed inside each box. Genotypes have been reported as they were described in the original studies. Gene polymorphisms or genotypes for which contradictory results have been reported are marked in bold. Genes polymorphisms included in the green boxes (left side) are those which have been indicated to favorably impact on patients' outcome. Further details, abbreviations legend and references are provided in the text. 


\subsection{TP53 and Its Regulators MDM2 and Mouse Double Minute 4 (MDM4)}

The significance of mutations and genetic abnormalities of the TP53 gene for bone and soft tissue sarcoma pathogenesis and progression has been supported by several studies, which have proven the high frequency and variability of TP53 mutations in HGOS [44,45]. However, recent WGS analyses have indicated that the significance of TP53 alterations in bone and soft tissue sarcomas could have been underestimated [46]. This fact has strengthened the interest for TP53 and its pathway as possible therapeutic targets, especially for tumors that, like HGOS, frequently present alterations of this gene [46].

The MDM2 gene, a crucial regulator of the TP53 protein stability and degradation, has been found to be amplified and overexpressed in a relevant number of HGOS [39,47].

Another major inhibitor of TP53 is MDM4, which encodes for a protein that, such as MDM2, binds to TP53, inhibiting its activity [48]. MDM4 amplification has been revealed in 35\% HGOS [39,49] and it has been associated to poor prognosis in HGOS, soft tissue sarcomas, and other cancers [50-52].

Inhibitors of MDM4, TP53-MDM2 interaction, or MDM2/MDM4 dual inhibitors have been tested in clinical trials or are presently under investigation [46], but their efficacy in HGOS must still be determined. While current TP53-targeted therapies have shown severe limitations in clinical settings, mostly due to induction of bone marrow suppression and other adverse side effects, they keep a great interest as candidate approaches that might be used to treat therapy-resistant bone and soft tissue sarcoma patients in the near future. However, obtaining details on tumor genotype of patients who may be potentially eligible for these treatments is mandatory prior starting any targeted therapy.

Although TP53 and MDM2 SNPs have been extensively reported as risk factors for HGOS [31,39,41,43,44,53-55], much fewer information is available about their impact on clinical outcomes of HGOS patients.

The TP53 rs1800372 (p.R213R), a rare synonymous variant leading to an exonic splice site change, was described to be associated with higher incidence of metastasis at diagnosis in European HGOS patients [32].

The TP53 rs1042522 Arg72Pro polymorphism (Pro/Pro versus wild-type Arg/Arg genotype) was reported to be associated with increased risk of relapse and to have an adverse prognostic value for event-free and overall survival in HGOS patients [40].

In a series of 210 HGOS Chinese patients, the GG genotype of the TP53 rs1042522 polymorphism was found to be associated with a shorter survival time compared with patients carrying the CC genotype [56].

The variant status of TP53_IVS2+38G/C rs1642785 polymorphism was reported to be associated with better event-free survival in a group of 126 HGOS [54].

Concerning $M D M 2$, a meta-analysis indicated that polymorphisms affecting this gene are related to HGOS risk, but do not seem to have effects on patients' survival, even if further studies are needed to confirm the last assumption [41].

\subsection{DNA Repair-Related Genes}

The altered activity of factors involved in the repair of drug-induced DNA damages can significantly influence either the resistance or sensitivity to DNA targeting drugs, including those used in HGOS chemotherapy $[57,58]$. Consequently, it is not surprising that polymorphisms of genes belonging to DNA repair pathways have proved to be associated with drug response, survival and toxicity in different tumors $[57,59]$.

The available scientific literature has shown that several polymorphisms affecting DNA repair genes appear to variably correlate with treatment response and/or survival also in HGOS, but the reported findings were sometimes contradictory, as summarized below.

The CC genotype of the ERCC1 rs11615 polymorphism was found to be associated with good response to cisplatin-based chemotherapy and better overall survival when compared to 
TT genotype [60-64]. However, other studies described the opposite evidence, being a better survival associated with the TT compared to CC genotype $[65,66]$.

Patients carrying the C allele of the ERCC1 rs3212986 polymorphism were described to have better event-free survival [67].

Association with poor response to chemotherapy was reported for the AC/CC genotype of the ERCC1 rs2298881 polymorphism [62], but another study provided partially opposite findings indicating that the AC/AA genotype associated with poor chemotherapy responsiveness [60].

Concerning the ERCC2 rs13181 polymorphism, the TT genotype was found to be associated with better treatment response and event-free survival compared to GT/GG genotype [68], but there were also studies reporting the correlation with a better event-free survival for the GG compared to TT genotype [69] or for the GG compared to AA genotype [70]. The AA genotype was also described to be associated with higher treatment response and increased overall survival compared with GG genotype [71].

An association with better event-free survival was reported for the GA/AA genotypes of ERCC2 rs1799793 polymorphism compared to GG genotype [69] and for patients with at least one polymorphic allele (GA/AA) [72]. In concordance with this evidence, other two studies showed that the AA genotype correlated with better response to chemotherapy and overall survival compared with the GG genotype [66,73].

Better response to cisplatin-based chemotherapy and overall survival was described for the TT genotype of the ERCC5 rs2296147 and rs1047768 polymorphisms [74-76].

The TT genotype and T allele of the nucleotide excision repair homolog (MMS19) rs29001322 polymorphism resulted to be associated with better response to cisplatin-based chemotherapy and increased overall survival $[74,76]$. However, the opposite evidence for TT genotype in relation to survival was reported in another study [75].

An association with worse outcome was found for patients carrying the C allele of the MSH2 rs4638843 polymorphism [77].

The nibrin (NBN) rs1805794+rs709816+rs1063054 CGA haplotype was found to be associated with shorter event-free survival compared with CAA haplotype [72].

Patients carrying the AC/CC genotypes of xeroderma pigmentosum complementation group $\mathrm{C}$ (XPC) rs2228001 polymorphism showed higher response rates to pre-operative chemotherapy [68].

Several studies performed on HGOS have recruited limited numbers of patients, as it is frequently the case for rare tumors. In the attempt to overcome, at least in part, this limitation, meta-analyses have been performed with the aim to support the translation of provided evidence into clinical practice.

In particular, three meta-analyses focused on the most frequently studied polymorphisms of nucleotide excision repair (NER) genes in HGOS [63,70,78].

Two of these studies confirmed that HGOS patients carrying the C allele of ERCC1 rs11615 polymorphism showed better response to chemotherapy in both Caucasian and Chinese populations mboxciteB63-ijms-833724,B78-ijms-833724. In Chinese HGOS patients, a higher chemotherapy response rate was also found for ERCC2 rs1799793 (AG + AA) genotypes [63]. The third meta-analysis indicated that the AA genotype of ERCC2 rs13181 polymorphism was associated with a better survival rate compared to the GG genotype in both Chinese and Caucasian HGOS patients [70].

In general, despite the additional information provided by meta-analyses, it can be concluded that the findings reported so far concerning DNA repair-related gene polymorphisms in HGOS must be further confirmed, in order to identify the possible reasons for discrepancy and, subsequently, to validate their predictive and prognostic value before being considered for a real clinical translation.

\subsection{Genes Involved in Drug Metabolism}

Chemotherapeutic agents are detoxified and, in the case of prodrugs, activated by several drug metabolizing enzymes (DMEs), which are responsible for their biotransformation in both tumor and normal cells [79]. It is therefore easily understandable that DMEs can significantly influence the tumor 
responsiveness to chemotherapy, as well as the susceptibility of normal tissues to treatment-related toxicities. Pharmacogenetic and pharmacogenomic analyses of DMEs in tumor patients may thus provide useful indications to modulate the use of chemotherapeutic drugs according to patients' genetic characteristics.

When considering the possible clinical impact of DMEs, the role of each enzyme for its specific drug biotransformation must be taken into account. For example, gene variations resulting in a DME function impairment can decrease the therapeutic activity of pharmacologically inactive prodrugs, which require bioactivation to become effective, but also be associated with a lower induction of toxicity in normal cells. On the other hand, regarding DMEs involved in drug detoxification, gene alterations associated with an impaired enzyme activity can determine an increased therapeutic effectiveness, but also a higher risk for collateral toxicity.

In the last 15 years, the number of genetic studies concerning DMEs in HGOS has been progressively increased and has provided some interesting information.

Glutathione S-transferase (GST) enzymes play a major role in the detoxification of a wide range of chemotherapeutic drugs [80] and are the DMEs that have most widely been studied in HGOS. Different polymorphisms of the GSTP1 gene have been reported to be associated with a variable enzyme ability to metabolize anticancer agents [81] and, for some of them, evidence of a possible clinical impact in HGOS has been reported, even if findings were sometimes contradictory or, at least, not completely concordant. This is the case for studies that analyzed the GSTP1 rs1695 polymorphism, which have provided discordant indications. The GSTP1 rs1695 AG + GG genotypes have mostly been reported to be associated with poor histological response and worse survival in HGOS patients treated with neo-adjuvant chemotherapy [82-86], but a large Chinese study showed that the GG genotype was related to good response to chemotherapy [71].

The most relevant, but again not always concordant, results concerning the other GST isoenzymes can be summarized as follows:

- The GSTM1 null allele was reported to be associated with an increased relapse rate in non-metastatic patients, and with poor survival in metastatic patients [87].

- The non-null allele of GSTT1 was correlated with poor survival in metastatic patients [87]. On the other hand, poor event-free survival was shown to be associated with the GSTT1 null allele in a study on Caucasian patients [85]. Partially in contrast with these findings, GSTM1 and/or GSTT1 null genotypes were reported to be associated with better survival rates in a Chinese study [86].

- The GSTM3*B allele of rs1799735 was reported to be associated with the presence of metastases at diagnosis, whereas the GSTM3*A allele rs1799735 emerged to be correlated with worse survival in patients presenting metastasis at clinical onset $[87,88]$.

The aforementioned body of evidence has been generated from analyses on germline pharmacogenetic variants, but the clinical impact of GSTs pharmacogenomic, somatic variants has also been assessed. In a study performed on tumor tissue from 66 HGOS patients, the GSTP1 rs 1138272 variant genotype proved to be associated with both shorter event-free and overall survival, whereas no association with survival was revealed for deletions of either GSTM1 or GSTT1 [72].

Meta-analyses about GST polymorphisms in HGOS provided apparently contradictory results. One of these studies [89] revealed significant associations between the AA genotype of GSTP1 rs1695 polymorphism and good tumor response, progression-free and overall survival. Another meta-analysis, however, did not find significant associations with clinical parameters of polymorphisms affecting GSTP1, GSTM3, and GSTT1 [90]. A third meta-analysis performed on 681 Chinese Han patients, did not find any association between GSTM1 and GSTT1 polymorphisms and chemosensitivity [91].

Other very important DMEs are those belonging to the cytochrome P450 (CYP) family. CYPs are involved in both anticancer drugs detoxification and prodrugs activation, therefore playing a key role in determining drug effectiveness and collateral toxicity [92]. Since these enzymes show a 
relevant genetic variability, CYPs polymorphic variants can lead to differences in treatment response and susceptibility to chemotherapy-associated toxicities.

The reported evidence with the most relevant clinical impact in HGOS concerns the CYP3A4 rs4646437 polymorphism [77]. The variant allele of CYP3A4 rs4646437 was shown to be associated with better treatment response and survival in HGOS patients treated with standard neoadjuvant chemotherapy protocols, most probably due to the reduced CYP3A4-mediated drug inactivation [77].

The variant genotype of the $C Y P 2 B 6^{*} 6$ (rs3745274 and rs2279343) polymorphism was found to be associated with a worse event-free survival, probably because of a decreased enzyme expression and a consequent decreased ifosfamide activation [54].

As a general conclusion, it can be stated that, despite this very promising body of results, stronger evidence is needed to definitely prove the clinical impact of DMEs genetic alterations in HGOS pathogenesis and prognosis.

\subsection{Genes Involved in Drug Transport}

Drug traffic into and out of cells is mediated by specific membrane transporters, which play a key role in determining tissue drug concentrations and, consequently, their therapeutic efficacy and toxicity on normal tissues of anticancer agents. Concerning HGOS, evidence of correlation with clinical parameters has been reported for transporters belonging to the ATP binding cassette (ABC) family. Several first- and second-line HGOS chemotherapeutic drugs are substrates of these transporters and, therefore, it is not surprising that polymorphisms affecting members of this family have been indicated as candidate biomarkers for a possible clinical translation. Gene polymorphisms that have reported to be significantly associated with therapy response and /or survival in HGOS can be summarized as follows:

- The TT genotype of the $A B C B 1$ rs1128503 polymorphism was related to good chemotherapy response and better survival in three studies $[83,93,94]$, but some discrepant observations were reported in other two analyses [82,95];

- $\quad$ The CT/TT genotypes of the ABCC2 rs717620 polymorphism were shown to be associated with a poor response to pre-operative chemotherapy [85], whereas the AA/GA genotypes of the $A B C C 2$ rs2273697 polymorphism correlated with worse event-free survival [54];

- The variant status of the $A B C C 2 \_1249 \mathrm{~A} / \mathrm{G}$ (rs2273697) polymorphism was reported to be associated with worse event-free survival [54];

- Association with poor response to first-line chemotherapy and worse survival was described for the TT genotype and T allele of the $A B C C 3$ rs4148416 polymorphism $[83,93,95]$;

- Worse survival was found to be associated with the $\mathrm{G}$ allele of the ABCC5 rs939338 polymorphism [77].

A meta-analysis confirmed the association of $A B C B 1$ rs1128503 (TT genotype) with good response and of $A B C C 3$ rs418416 (T allele) with poor response to chemotherapy in Caucasian populations [96]. In summary, again, if promising findings for a possible clinical translation have been reported for $A B C$ transporters, further validation is warranted to validate the reliability of these candidate genetic markers.

\subsection{Polymorphisms of Genes Involved in Antifolate Drugs Metabolism}

One of the most widely used drug for HGOS treatment is antifolate methotrexate (MTX). Two other antifolates, trimetrexate and pemetrexed, have been used in second-line chemotherapy protocols to treat recurrent HGOS patients, but their activity proved to be unfortunately modest [97-99].

Pharmacogenetic and pharmacogenomic studies in HGOS have focused on the analysis of polymorphisms affecting genes that play important roles in the metabolism of MTX and other antifolate drugs. The data with evidence of clinical correlations in HGOS are summarized below. 
The GG genotype of the rs1053129 polymorphism of the dihydrofolate reductase (DHFR) gene, the main target of MTX, was reported to be associated with a higher probability to develop metastasis during follow-up [85].

The rs1051266 polymorphism of the solute carrier family 19 folate transporter member 1 (SLC19A1) gene (also known as reduced folate carrier, RFC or reduced folate carrier 1, RFC1), a MTX membrane transporter, was reported to be associated with clinical outcome, showing that patients bearing the allele $G$ had better survival and lower predisposition to develop metastases $[85,100]$.

The AG/AA genotype of the rs2236225 polymorphism of the methylenetetrahydrofolate dehydrogenase (NADP+ dependent) 1 (MTHFD1) gene, a folate cycle enzyme which is involved in de novo purine synthesis, was found to be associated with good histological response after preoperative chemotherapy [85].

The TT genotype of the rs11545078 polymorphism of the gamma-glutamyl hydrolase $(G G H)$ gene, an enzyme which catalyzes the hydrolysis of folylpoly-gamma-glutamates and anti-folylpoly-gamma-glutamates influencing the overall effectiveness of MTX, was found to be associated with poor survival [54].

Another gene that has been studied in HGOS is the solute carrier organic anion transporter family member 1B1 (SLCO1B1), which is the main uptake transporter of MTX in the liver and one of the most important factors influencing MTX clearance. Patients with at least one polymorphic allele of SLCO1B1 rs4149056 and rs11045879 polymorphisms exhibited longer event-free survival compared to patients with two wild-type alleles [101].

By considering the studies reported so far in HGOS concerning polymorphisms affecting genes involved in the MTX and folate pathways, it must be underlined that the numbers of patients carrying genotypes associated with unfavorable treatment response or prognosis were invariably low, and, therefore, all this body of evidence needs further validation in larger patients series before an effective translation into clinical practice.

\section{Gene Polymorphisms Associated with Toxicities}

High-dose methotrexate often causes bone marrow suppression and liver and renal toxicities, whereas anthracyclin-induced cardiotoxicity and cisplatin-induced ototoxicity have been reported [102]. Mainly candidate gene and pathway driven approaches have revealed some recurrent associations between gene variations and collateral toxicities in HGOS patients [103]. Confirmation of this evidence in a larger patient series is needed before this knowledge can be translated into personalized treatment schedules, except for cisplatin-induced ototoxicity and doxorubicin-induced cardiotoxicity for which international recommendations have already been provided [104,105]. Since the possible functional role of most of these genetic variants is not yet clear and can be different in normal and tumor cells, further functional studies are needed to elucidate their biological consequences in association with cell death, drug detoxification and transport in both normal and tumor tissue.

\subsection{Haematological Toxicities}

As shown in Figure 2, genes reported in association with hematological toxicity belong to the folate or NER pathways, the ABC transporter family or to DMEs. Pharmacogenomics of genes belonging to the folate metabolism or transport in HGOS patients have recently been reviewed [106]. 


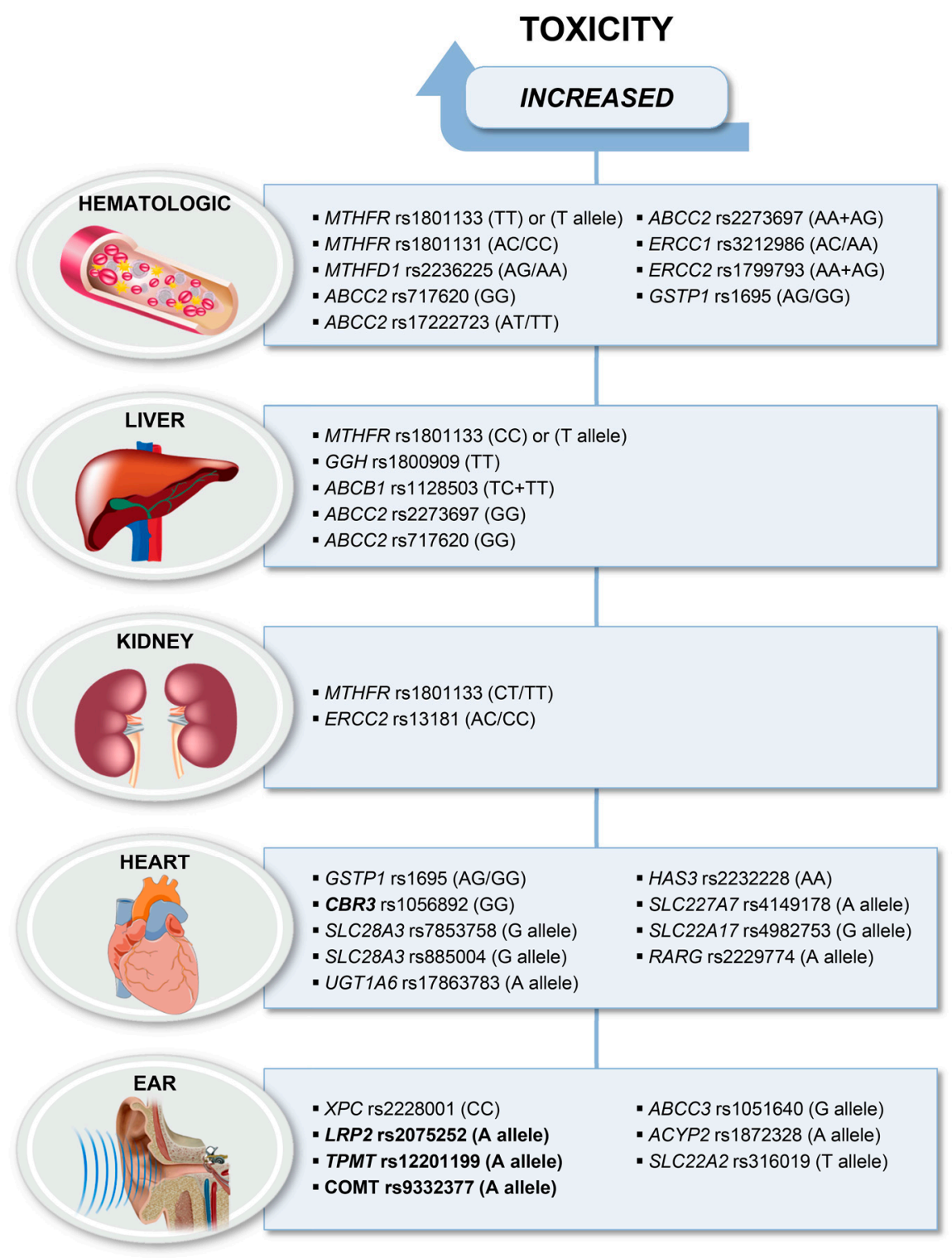

Figure 2. Pharmacogenetic variations impacting on chemotherapy-induced toxicities in high-grade osteosarcoma (HGOS). Genes, polymorphisms and corresponding genotypes (inside parenthesis) are listed inside each box. Genotypes have been reported as they were described in the original studies. Genes polymorphisms or genotypes for which contradictory results have been reported are marked in bold. Further details, abbreviations legend and references are provided in the text.

The 5,10-methylene tetrahydrofolate reductase (MTHFR) rs1801133 polymorphism leads to a $C$ to T substitution at nucleotide position 677 , with the result of a substitution of valine for alanine in the functional enzyme and a decreased enzymatic activity. The TT genotype was significantly associated with grade 3-4 hematologic toxicity in 96 pediatric HGOS patients [107]. In a recent study, the variant $\mathrm{T}$ allele of this polymorphism was reported to correlate with higher degrees of hematologic toxicities in 59 Han Chinese patients with HGOS [108].

A second polymorphism of the MTHFR gene, rs1801131, leads to an A to C substitution at nucleotide 1289 and also to reduced enzyme activity. The AC/CC genotypes were found to be associated with anemia and with severe leukopenia in 50 [85] and 57 HGOS patients [54].

AG/GG genotypes of a third gene polymorphism belonging to the folate pathway, the MTHFD1 rs2236225, were reported to be associated with anemia [85]. 
Among the $\mathrm{ABC}$ transporter gene family, three polymorphisms of the $A B C C 2$ gene, rs717620 (GG) [101], rs17222723 (AT/TT) [85] and rs 2273697 (AA + GA) [54,109] have been reported to be associated with hematological toxicities.

The AC/AA genotypes of ERCC1 rs3212986 and the AG/GG genotypes of GSTP1 rs1695 were reported to be associated with leukopenia in one study [85]. Another polymorphism of the NER pathway, the AA/AG genotype of ERCC2 rs1799793, was reported in association with thrombocytopenia [54].

\subsection{Liver Toxicity}

The MTHFR rs1801133 polymorphism has been reported by different groups to be associated with liver toxicity [110]. One study carried out in patients after high-dose MTX-therapy found a significant association between the T allele and liver toxicity in 49 patients with HGOS [111]. This association, however, was not confirmed in the subsequent meta-analysis, including seven studies with a total of 1044 patients (148 with HGOS), whereas a recent study on 59 Han Chinese patients with HGOS found the variant T allele of MTHFR rs1801133 being associated with higher degrees of liver toxicity [108].

Apparently contradictory results were reported in a Norwegian study on 62 patients with HGOS [100]. The CC genotype of MTHFR rs1801133 was associated with a higher degree of liver toxicity. Although statistically not significant, patients who could not receive the whole number of MTX cycles because of collateral toxicity were more frequently carriers of the CC and AC genotypes.

A very small descriptive study of 18 patients, including seven with HGOS who had developed severe clinical or liver toxicity measured by elevated alanine transaminase (ALT) levels revealed that rare alleles of MTHFR rs1801133 and thymidylate synthase (TS) rs34743033 were more frequent in HGOS patients compared to the normal population [112].

The TT genotype of GGH rs189909, another gene of the folate pathway, was reported in association with hepatotoxicity in one study [54].

Among the $\mathrm{ABC}$ transporter genes, two polymorphisms of the $A B C C 2$ gene, rs717620 (GG) [101] and rs2273697 (GG), and $A B C B 1$ rs1128503 (TC + TT) have been reported to be associated with liver toxicity [54].

\subsection{Nephrotoxicity}

Although renal failure is frequent when high-dose MTX and cisplatin are administered, only few studies could find associations with genetic polymorphisms. Mueller and co-workers [113] described one patient who was homozygous for the variant of MTHFR rs1801133 (TT) but wild-type for MTHFR rs1801131 (AA). They concluded that the association between MTHFR rs1801133 TT and severe MTX-related toxicity could be explained by disturbances in the folate status and by prolonged MTX exposure due to delayed MTX clearance.

One study reported that patients with the variant genotypes GA/AA of SLC19A1 rs1051266 had significantly lower MTX plasma levels at 48 and $72 \mathrm{~h}$, whereas the GG genotype was associated with higher plasma levels and nephrotoxicity [114].

Similar evidence was reported in 50 HGOS patients carrying the variant allele of MTHFR rs 1801133 (CT/TT) and of ERCC2 rs13181 (AC/CC) [85]. For both polymorphisms, a trend for association with early nephrotoxicity was found.

\subsection{Cardiotoxicity}

Pharmacogenetic studies of anthracycline-induced cardiotoxicity (ACT) in patients with HGOS have recently been reviewed [103]. First, evidence was provided by a candidate gene study in 50 patients with HGOS that the GSTP1 rs1695 variant allele was associated with cardiotoxicity [85], but this result was not confirmed by others.

Several large studies on pediatric cancer patients including HGOS have focused on drug metabolism genes with possible impact on cardiotoxicity (Figure 2). Carbonyl reductases (CBRs) are involved in the reduction of anthracyclines. The variant GG genotype of the CBR3 rs1056892, 
which influences the synthesis of these metabolites, was associated with cardiomyopathy in patients who received low-to-moderate-dose but not in patients who received high-dose anthracyclines [115]. The authors concluded that there was no safe dose for patients homozygous for the variant $G$ allele. However, this association was not confirmed in a large international study using a customized assay containing almost 3000 SNPs of 220 key biotransformation genes [116]. They identified a strong association between the variant $\mathrm{G}$ allele of solute carrier family 28 member 3 (SLC28A3) rs7853758 and ACT which was confirmed in a subsequent study by the same authors [117]. In addition, associations between ACT and a second variant of SLC28A3, rs885004, and the variant rs17863783 in UDP glucuronosyltransferase 1 A6 (UGT1A6) were confirmed in this replication study including 16 patients with HGOS of the total cohort of 202 pediatric cancer patients. In another large study including pediatric patients with bone tumors, using a cardiovascular SNP array to profile common SNPs in 2100 genes considered relevant to de novo cardiovascular disease, the AA genotype of rs2232228 in the hyaluronan synthase 3 (HAS3) gene conferred an increased risk for cardiomyopathy compared to the AA genotype [118]. This study did not include the CBR3 and SLC28A3 variants of the previous studies.

In order to identify new variants and to improve their previously reported genotype-guided risk prediction model, Visscher and co-workers genotyped two cohorts of pediatric cancer patients for 4578 SNPs in absorption, distribution, metabolism, excretion (ADME) and toxicity genes [119]. Two novel SNPs, rs4982753 in solute carrier family 22 member 17 (SLC22A17) and rs4149178 in solute carrier family 22 member 7 (SLC22A7), were identified to be significantly associated with ACT. The same group performed a GWAS study in which they identified the new non-synonymous variant rs2229774 in the retinoic acid receptor $\gamma(R A R G)$ gene to be associated with ACT in childhood cancer [120]. All this evidence has formed the basis for the recommendations published by the same authors to guide genetic testing in pediatric patients in order to avoid ACT (PharmGKB ID PA166159180). They state that RARG rs2229774, SLC28A3 rs7853758 and UGT1A6 rs17863783 variants currently have the strongest and the most consistent evidence for association with ACT.

A recent study carried out on 167 anthracycline-exposed childhood cancer survivors (75 cases and 92 matched controls with different diagnosis including 40 with bone tumors) reported that patients who had the GSTM1 null genotype had a significantly higher risk to develop cardiomyopathy [121]. GSTM1 expression downregulation in patients with the null phenotype in peripheral blood was confirmed by array and RNA-Seq analyses. In addition, gene expression analysis of human-induced pluripotent stem cell cardiomyocytes from patients who had ACT showed significantly reduced expression of GSTM1 compared to those from patients without ACT. The authors conclude that also GSTM1 could be considered in a risk-prediction model to facilitate the identification of childhood cancer survivors who are at increased risk of anthracycline-related cardiomyopathy.

\subsection{Ototoxicity}

Pharmacogenetic studies reporting data regarding cisplatin-induced ototoxicity in patients with HGOS were mainly candidate gene-driven focusing on genes expressed in different tissues of the ear, involved in drug detoxification or on DNA repair genes [103]. Since many of them reported protective effect of gene variants which were not verified in replicate studies, Figure 2 shows only those polymorphisms that were found to be significantly associated with ototoxicity.

In a subgroup of 32 HGOS patients, the CC genotype of XPC rs2228001 was associated with ototoxicity [68]. The variant allele A of the LDL receptor related protein 2 (LRP2) rs2075252 was reported in association with ototoxicity in a series of 38 patients with HGOS [122], but no evidence of this association was found in the study by Ross and co-workers [123]. Another candidate-gene study reported that the variant $\mathrm{T}$ allele of the solute carrier family 22 member 2 (SLC22A2) rs316019 was associated with hearing loss in 41 patients with HGOS [124].

Variants of thiopurine S-methyltransferase TPMT (rs12201199, rs180046 and rs1142345) and catechol O-methyltransferase (COMT) (rs4646316 and rs9332377) were reported to be associated with ototoxicity after treatment with cisplatin in different cancers, including HGOS [123,125]. In the 
only study of exclusively patients with HGOS $(n=139)$, no associations between these variants and increased risk of ototoxicity were reported. However, the meta-analysis including a total of 664 patients revealed that the COMT rs4646361 was the only one that remained significant but associated with less risk $(\mathrm{OR}=1.52)$ as predicted in the other studies $(\mathrm{OR}=2.52)$ [126]. Although initially promising, variants in the COMT and TPMT genes do not seem to play major roles as risk factors to develop cisplatin-induced ototoxicity and therefore stronger markers for clinical decision making are warranted. However, pharmacogenetic testing for the TPMT alleles *2 (rs1800462), *3A (rs1800460 and rs1142345), *3B (rs1800460) or *3C (rs1142345) is recommended by the Canadian Pharmacogenomics Network for Drug Safety in pediatric cancer patients when prescribing cisplatin (PharmGKB ID PA166170751).

The acylphosphatase 2 (ACYP2) rs1872328 was reported first in children with brain tumors [127] and was then confirmed in patients with HGOS [128].

Protective effects were reported for the GSTM3* rs1799735 allele in a group with normal hearing [129] and for the $G$ alleles of Otos rs77124181 (c.-192-182C>G) and rs2291767 (c.-192-22A>G) [130].

\subsection{Other Treatment-Related Toxicities}

In addition to the toxicities that can result also in the long-term insufficiencies described above, several polymorphisms have been reported in association with less severe but frequent toxicities influencing the quality of life during chemotherapy treatment. In a study on tumor tissue obtained from 66 HGOS patients, the CC genotype of XRCC3 rs 861539 was associated with nausea [72]. The same study reported the GA/AA genotype of ERCC2 rs1799793 to be associated with nausea and gastrointestinal toxicity [72]. Similar evidence was reported for the CC/CT genotypes of XRCC3 rs861539 being associated with nausea and vomiting, as was reported also for the GG genotype of ABCC2 rs3740066 [54].

The following polymorphisms were reported in association with mucositis: the T allele of DHFR rs1650723 and the CT genotype of ABCG2 rs2231135 [100], the TT genotype of ERCC1 rs1615 and CT/CC genotypes of $A B C B 1$ rs1045642 after MTX treatment [85], and the GG genotype of SLC19A1 rs1051266 [114].

Two studies reported polymorphisms in association with fever: the AC/AA genotypes of ERCC1 rs3212986 [54] and the T allele of MTHFR rs1801133 [108].

\section{Polymorphisms of Non-Coding RNAs}

Non-coding sequences represent up to $98 \%$ of the human genome and, like coding DNA, can be affected by genetic changes [131]. Since the majority of non-coding elements can influence gene expression, genetic variants of non-coding regions may become relevant for clinical care through the altered modulation of gene activity exerted by their products [131]. Among non-coding elements, those that have been most extensively studied in HGOS are microRNAs (miRNAs) and long non-coding RNAs (lncRNAs). Although some evidence of the possible involvement of non-coding RNAs in HGOS pathogenesis has been reported [132-135], very few data have been provided so far regarding the potential impact of polymorphisms affecting miRNAs or lncRNAs on HGOS survival.

A recent study evaluated the correlation between SNPs of hsa-miR-124a and risk and prognosis of HGOS [136]. SNPs of hsa-miR-124a were assessed on 174 HGOS patients and 150 healthy people. The CG+GG genotype of the hsa-miR-124a rs531564 polymorphism proved to be associated with a decreased risk for HGOS development and a higher five-year survival rate compared to CC genotype [136].

Moreover, NGS techniques have shown that a single miRNA locus can generate multiple distinct miRNA isoforms (isomiRs) that differ in length, sequence composition or both of them. Multiple lines of evidence suggest that the profile of isomiRs is cell- and tissue-specific, and, therefore, can be used as a biomarker for many diseases, including cancers [137]. Studying isomiRs is therefore expected to highlight new important biomarkers, since it has been indicated that they play important roles 
in a wide range of biological processes, including promotion of apoptosis and repression of tumor progression [137].

\section{Preclinical Models and Public Datasets}

The establishment of patient-derived tumor xenografts (PDXs or PDTXs) has become an innovative approach to overcome the frequent lack of adequate experimental models for HGOS [138,139]. Therefore, two recent studies will be discussed here. Nanni and co-workers [140] implanted fresh osteosarcoma or Ewing sarcoma tumor specimens sub-cutaneously at the level of trans-scapular brown fat of 5-11 week-old NOD Scid gamma (NSG) male mice. When the tumor reached a maximal volume of $2.5 \mathrm{~cm}^{3}$ mice were sacrificed. Established PDXs were also implanted in BALB/c Rag2-/-;Il2rg-/- (RGKO) mice. In the study by Sayles and co-workers [141], fresh or frozen osteosarcoma tumor samples were implanted in the sub-renal capsule of NSG mice after having dipped them into Matrigel. The tumor growth was monitored up to one year. Both studies reported the generation of PDX-derived cell lines with [141] or without [140] prior enrichment for human cells.

In the study by Nanni and co-workers [140], the morphological characterization and expression of two biomarkers, SATB homeobox 2 (SATB2) and ABCB1, revealed by immunohistochemistry, as well as gene expression profiling by the Agilent whole human genome microarray (\#G4851C) showed remarkable similarity between the patient's tumor and PDX, which was maintained at least until the sixth in vivo generation. Genes differentially expressed in the original tumor compared to the corresponding PDXs prevalently belonged to immune functional categories, due to the gradual replacement of human leukocytes by murine leukocytes during growth in mice. PDX-derived cell lines maintained the features of the original tumor at a lower degree indicating that adaption to in vitro growth has a higher impact on the molecular profile than adaption to in vivo growth. Primary cell cultures appeared less reliable than PDXs, which might be attributed to the high genetic instability of HGOS.

In the study by Sayles and co-workers [141], WGS was performed on 30 tumor samples and corresponding germline DNAs obtained from 23 patients. This dataset was expanded by the non-overlapping dataset of 33 samples obtained from 31 patients [142] with the aim to identify recurrent copy number $(\mathrm{CN})$ alterations in druggable and clinically actionable cancer genes. The most commonly amplified genes were MYC (39\%) and cyclin E1 (CCNE1;33\%), followed by RAD21 cohesin complex component (RAD21; 38\%), VEGFA (23\%), Aurora kinase B (AURKB; 13\%) and cyclin-dependent kinase $4(C D K 4 ; 11 \%)$. Recurrent deletions, structural variations (SV) and somatic nucleotide variants (SNV) were found most frequently in the tumor suppressor genes TP53 (74\%), RB1 (64\%) and phosphatase and tensin homolog (PTEN; 56\%). Fifteen PDX models were sequenced, where possible, of multiple passages and data were compared with the corresponding primary tumors. These analyses revealed that CN changes in PDX were highly correlated with those found in the corresponding primary tumors. In cases with RNA-sequencing data, a positive correlation was found between somatic copy number aberrations (SCNAs) and gene expression between the PDX and their matched primary tumor. In general, genes with highly increased CNs were also overexpressed.

In both studies, PDX-bearing mice were successfully used for in vivo drug testing. Summarizing, establishment of HGOS-derived PDXs is expensive and time-consuming, thus impossible to be translated directly to the clinics. However, well characterized panels of matched tumors, PDXs and cell lines from the same patient will serve as important experimental models not only to increment our molecular knowledge of this tumor and to study its evolution, but especially for testing innovative therapeutic approaches [143-145]. Sayles and co-workers [141] demonstrated successfully the utility of a target genome-informed approach for the identified target genes MYC, Cyclin-E, CDK4, AURKB and the phosphatidylinositol 3 kinase-AKT serine/threonine kinase-mammalian target of rapamycin (PI3K-AKT-mTOR) and VEGF pathways.

To our knowledge, so far pharmacogenomic studies have generally been performed on clinical tumor specimens and not on experimental models. The same holds true for 3D cell culture or 
organoids. However, it is expected that all these innovative experimental models, which better mimic the clinical situation compared to classical 2D cell cultures [146,147], would maintain the patients' pharmacogenetic genotype. Therefore, PDX-derived cell lines could eventually become a new source for pharmacogenomic-driven drug-testing in the field of translational research and hopefully applicable soon also in the clinics.

Integrative elaboration of WGS data with multiple datasets and defined clinical parameters is an innovative approach that permits to better identify pathway associations and to provide the opportunity for discovery of clinically actionable variants and thus overcomes the limitations of gene or pathway driven studies. This approach has recently been applied to two germline datasets, Therapeutically Applicable Research to Generate Effective Treatments (TARGET) and INOVA, of patients with HGOS treated with standard methotrexate-adriamycin-cisplatin therapy [148]. Haplotype and single SNP analyses were performed, and sanger sequencing technique was used for data validation. Intronic and intergenic hotspot regions from 26 genes that were common to both data sets were significantly associated with relapse. A total of 281 variants were significantly associated with tumor necrosis. Five of these were also significantly associated with worse survival. It is noteworthy that none of these genes, SLC22A1, solute carrier family 22 member 8 (SLC22A8), UDP glucuronosyltransferase family 2 member B15 (UGT2B15) and carbohydrate sulfotransferase 12 (CHST12), has ever been studied in candidate or pathway driven approaches.

The advantage of public available datasets is that they can easily be downloaded and elaborated without the need of conducting one's own experiments, thus avoiding high costs and technical problems. Elaborating the same data sets by different algorithms enables bioinformatics to collaborate and to improve their tools.

\section{Social-Economical Aspects of Pharmacogenomics-Based Precision Medicine in HGOS}

Most anticancer drugs, including those used in HGOS chemotherapy, have a narrow therapeutic window and exhibit variable efficacy among patients which can result in treatment failure or the development of severe toxicities.

While the consequences of treatment failure are easily understandable, those of adverse reactions to chemotherapeutic drugs are frequently underestimated. Globally, the development of chemotherapy-related toxicities has been calculated to be responsible for about $7 \%$ of all hospital admissions in Europe and for more than 100,000 death/year in the United States [149,150]. Moreover, a large survey performed in the United States during the 1990s indicated that adverse drug toxicities ranked from fourth to sixth as leading cause of in-hospital mortality [150], and a follow-up study performed in 2010 did not show any improvement [151].

It has also to be taken into consideration that toxicity reactions lead to additional pharmacologic treatments to counteract their effects, which are frequently associated with a progressively worsening of patients' quality of life and a significant increase of costs for medical care, both of which cause growing concerns about the rising expenses in oncology.

Tailored treatments (which are included in the so-called personalized medicine or precision medicine approaches), in which biomarkers are used to match therapies to specific patient characteristics [152], may overcome at least part of these problems. Treatments modulated on the basis of individual patients' characteristics are therefore particularly warranted to maximize the efficacy and safety of each therapeutic regimen and, consequently, to also reduce costs. The promise of pharmacogenetics and pharmacogenomics is thus in line with this scenery.

Present drug therapies of HGOS encounter all the aforementioned problems, which are additionally enhanced by the fact that this sarcoma mainly affects young people. Like in other tumors, several scientific, social and economic aspects have to be considered to define the actual feasibility of pharmacogenetics/pharmacogenomics-based precision medicine in HGOS. 
First, once predictive biomarkers have been sufficiently validated, before translating them to clinical practice it will be necessary to assess their prognostic influence in each patient subgroup and among different ethnicities in order to estimate their actual clinical value.

Another item to be considered is the cost of the biomarker test(s), which should be characterized by high sensitivity and specificity, in order to rule out or reduce as much as possible the occurrence of false-negative or false-positive results.

The costs of agents used for each biomarker(s)-driven treatment arm have also to be quantified, and programs for reimbursement of expenses for both biomarker test(s) and treatment modulation need to be established inside each country or, even, each institution.

On the other hand, it has to be considered that biomarker(s)-driven therapies will have to be considered for the small fraction of those HGOS patients, who did not sufficiently respond to conventional treatments. Therefore, for a rare tumor like HGOS, the number of patients that may be recruited inside these protocols will remain low. This fact may have both positive and negative consequences. For pharmaceutical companies producing the agents for tailored therapies, this fact can appear as poorly attractive, because of the small market and sales volume. For national-regional health systems, however, this situation may be considered as acceptable because the therapies costs will be more affordable due to the low patient numbers.

Precision medicine in HGOS may also take advantage from the development of nanomedicine and nanovectors. Since nanomedicine can modulate the biodistribution at the target site of anticancer drugs, thereby reducing their toxicity, its development will be of great help to indicate new methods of cancer treatment [153]. Nanoparticles loaded with different chemotherapeutic drugs have indeed been demonstrated to exhibit relevant anticancer activity in preclinical settings of lymphoma, glioma, and pediatric HGOS [153]. Although nanoplatforms for the delivery of chemotherapeutic drugs, small RNA molecules, photothermal therapeutics and immunotherapeutics should be further improved $[153,154]$, the recent advances achieved in nanomedicine and nanovectors research offer the possibility to develop novel therapeutic approaches which may be considered for specific subgroups of HGOS patients stratified according their pharmacogenetic and pharmacogenomic characteristics.

\section{Future Directions}

Traditionally, pharmacogenetic and pharmacogenomic studies have focused on a few or on a small number of candidate genes, generally selected on the basis of their involvement in mechanisms related to drug action, resistance, or metabolism in either tumor or normal tissues. This approach, when applied to HGOS, has provided a series of evidence of possible clinical impact, most of which (if not all) needs, however, to be further validated.

The body of information concerning single candidate genes may further be implemented by defining genetic risk scores, which consider multiple genetic variants that individually contribute to a specific phenotype and may increase their clinical impact when considered together.

The future translation to HGOS clinical practice of pharmacogenetic and pharmacogenomic provided evidence needs to proceed along some necessary steps.

First, ongoing clinical trials should incorporate pharmacogenetic and pharmacogenomic analyses in order to validate the findings reported in single, frequently not large, studies or emerged from preclinical experimental models.

Only once a marker or a group of markers will be validated, it may be proposed for a genetically-guided decision of personalized therapies aimed to enhance treatment success rate and simultaneously decrease the frequency of collateral toxicities, with a consequent improvement of patients' quality of life and a reduction of health care costs.

\subsection{Genetic Testing and Clinical Trials}

Genetic testing of patient-derived tumor cells can be used to identify specific therapeutic targets and, consequently, to identify patients who may benefit from treatments targeting their specific tumor 
genetic alterations. By using this approach, several MATCH clinical trials (targeted therapy directed by genetic testing in treating pediatric patients with relapsed or refractory advanced solid tumors, non-Hodgkin lymphomas, or histiocytic disorders; ClinicalTrials.gov Identifier: NCT03155620) have been launched and are presently active and ongoing in HGOS (Table 2). The pediatric MATCH screening trials are a complex of phase II clinical studies, in which treatment is directed by genetic testing. These trials are recruiting pediatric patients with solid tumors (including HGOS), non-Hodgkin lymphomas, or histiocytic disorders, who have progressed following at least one line of standard systemic therapy and/or for whom no standard rescue treatments are available.

Table 2. List of the pediatric MATCH screening trials that are presently active and recruiting patients with relapsed or refractory advanced solid tumors, including high-grade osteosarcoma. All trials are carried out in the USA. Time period refers to the actual study start date and estimated study completion date.

\begin{tabular}{|c|c|c|c|}
\hline $\begin{array}{c}\text { ClinicalTrials.Gov NCT } \\
\text { Identifier }\end{array}$ & Drug & $\begin{array}{c}\text { Mechanism of Drug Action and } \\
\text { Trial Description }\end{array}$ & $\begin{array}{l}\text { Stage of Development } \\
\text { (Time Period) }\end{array}$ \\
\hline NCT03210714 & $\begin{array}{c}\text { Erdafitinib } \\
(J N J-42756493)\end{array}$ & $\begin{array}{l}\text { Inhibition of FGFR with negative } \\
\text { effects on tumor cell growth and } \\
\text { angiogenesis. } \\
\text { This trial studies the activity of } \\
\text { erdafitinib in patients with FGFR } \\
\text { gene mutations, who are affected } \\
\text { by disseminated tumors. }\end{array}$ & $\begin{array}{c}\text { Phase II } \\
(11 / 2017-12 / 2024)\end{array}$ \\
\hline NCT03213665 & $\begin{array}{l}\text { Tazemetostat } \\
\text { (EPZ-6438) }\end{array}$ & $\begin{array}{c}\text { Inhibition of the activity of human } \\
\text { polycomb repressive complex } 2 \\
\text { containing wild-type } \\
\text { histone-lysine } \\
\text { N-methyltransferases EZH1 and } \\
\text { EZH2, with a consequent } \\
\text { inhibition of tumor cells growth. } \\
\text { This trial is intended to assess the } \\
\text { activity of tazemetostat in patients } \\
\text { with EZH2, SMARCB1, or } \\
\text { SMARCA4 gene mutations, who } \\
\text { are affected by disseminated } \\
\text { tumors. }\end{array}$ & $\begin{array}{c}\text { Phase II } \\
(07 / 2017-09 / 2024)\end{array}$ \\
\hline NCT03213678 & $\begin{array}{l}\text { Samotolisib } \\
\text { (LY3023414) }\end{array}$ & $\begin{array}{c}\text { Inhibition of PI3K/AKT/mTOR } \\
\text { pathway, producing negative } \\
\text { effects on the growth of cancer } \\
\text { cells. } \\
\text { This trial evaluates the activity of } \\
\text { samotolisib in patients with TSC } \\
\text { or PI3K/mTOR mutations, who } \\
\text { developed metastasis or local } \\
\text { recurrences, or who are refractory } \\
\text { to conventional treatments. }\end{array}$ & $\begin{array}{c}\text { Phase II } \\
(07 / 2017-09 / 2024)\end{array}$ \\
\hline NCT03220035 & $\begin{array}{l}\text { Vemurafenib } \\
\text { (PLX40321; } \\
\text { trade name } \\
\text { Zelboraf }^{\circledR} \text { ) }\end{array}$ & $\begin{array}{l}\text { Inhibition of the mutated B-Raf } \\
\text { protein, interrupting its } \\
\text { stimulation of cell growth. } \\
\text { This trial evaluates how } \\
\text { vemurafenib works in treating } \\
\text { patients with BRAF V600 } \\
\text { mutations who are affected by } \\
\text { tumors that have disseminated in } \\
\text { the body or do not respond to } \\
\text { conventional treatments. }\end{array}$ & $\begin{array}{c}\text { Phase II } \\
(07 / 2017-12 / 2023)\end{array}$ \\
\hline
\end{tabular}


Table 2. Cont.

\begin{tabular}{|c|c|c|c|}
\hline $\begin{array}{c}\text { ClinicalTrials.Gov NCT } \\
\text { Identifier }\end{array}$ & Drug & $\begin{array}{c}\text { Mechanism of Drug Action and } \\
\text { Trial Description }\end{array}$ & $\begin{array}{l}\text { Stage of Development } \\
\text { (Time Period) }\end{array}$ \\
\hline NCT03233204 & $\begin{array}{c}\text { Olaparib } \\
\text { (AZD-2281, } \\
\text { MK-7339, trade } \\
\text { name } \\
\left.\text { Lynparza }^{\circledR}\right)\end{array}$ & $\begin{array}{c}\text { Inhibition of PARP1 and } \\
\text { consequent impairment of DNA } \\
\text { repair activity. } \\
\text { This trial assesses the efficacy of } \\
\text { olaparib in treating patients with } \\
\text { hereditary BRCA1 or BRCA2 } \\
\text { mutations, leading to defects in } \\
\text { DNA damage repair activity. } \\
\text { The trial recruits patients who } \\
\text { have developed metastasis or local } \\
\text { recurrences, or who are refractory } \\
\text { to conventional treatments. }\end{array}$ & $\begin{array}{c}\text { Phase II } \\
(07 / 2017-09 / 2024)\end{array}$ \\
\hline NCT03526250 & $\begin{array}{l}\text { Palbociclib } \\
\text { (PD-0332991, } \\
\text { trade name } \\
\text { Ibrance }^{\circledR} \text { ) }\end{array}$ & $\begin{array}{c}\text { Selective inhibition of the } \\
\text { cyclin-dependent kinases CDK4 } \\
\text { and CDK6. } \\
\text { By inhibiting CDK4 and CDK6, } \\
\text { palbociclib may stop the growth of } \\
\text { cancer cells. } \\
\text { This trial evaluates how } \\
\text { palbociclib works in treating } \\
\text { patients with RB1-positive tumors } \\
\text { which have disseminated in the } \\
\text { body or do not respond to } \\
\text { conventional treatments. }\end{array}$ & $\begin{array}{c}\text { Phase II } \\
(06 / 2018-06 / 2025)\end{array}$ \\
\hline NCT03698994 & $\begin{array}{c}\text { Ulixertinib } \\
\text { (BVD-523; } \\
\text { VRT752271) }\end{array}$ & $\begin{array}{l}\text { Inhibition of ERK1/2 kinases, } \\
\text { belonging to the MAPK pathway. } \\
\text { By inhibiting cancer cells } \\
\text { harboring mutations in the MAPK } \\
\text { pathway, ulixertinib may stop } \\
\text { tumor growth. } \\
\text { This trial is intended to estimate } \\
\text { the activity of ulixertinib in } \\
\text { treating patients with } \\
\text { disseminated tumors, who present } \\
\text { genetic alterations in the MAPK } \\
\text { signaling pathway. }\end{array}$ & $\begin{array}{c}\text { Phase II } \\
(10 / 2018-12 / 2025)\end{array}$ \\
\hline \multicolumn{4}{|c|}{$\begin{array}{l}\text { AKT, AKT serine/threonine kinase; BRCA, breast related cancer antigen; } C D K \text {, cyclin-dependent kinase; } E R K, \\
\text { extracellular signal-regulated kinase; } E Z H 1 \text {, enhancer of zeste } 1 \text { polycomb repressive complex } 2 \text { subunit; EZH2, } \\
\text { enhancer of zeste } 2 \text { polycomb repressive complex } 2 \text { subunit; FGFR, fibroblast growth factor receptor; } m T O R, \\
\text { mammalian target of rapamycin; MAPK, mitogen-activated protein kinase; PARP1, poly (ADP-ribose) polymerase 1; } \\
\text { PI3K, phosphatidylinositol 3-kinase; SMARCB1, SWI/SNF related matrix associated actin dependent regulator of } \\
\text { chromatin, subfamily B, member 1; SMARCA4, SWI/SNF related matrix associated actin dependent regulator of } \\
\text { chromatin, subfamily A, member 4; B-Raf, B-Raf proto-oncogene, serine/threonine kinase; RB1, RB transcriptional } \\
\text { corepressor } 1 \text { (also known as retinoblastoma gene 1); TSC, TSC complex subunit. }\end{array}$} \\
\hline
\end{tabular}

Similarly, NGS technologies applied to pharmacogenetics and pharmacogenomics are also expected to provide information that can be translated to clinical care. Some experience in improving drug safety and efficacy by means of the so-called genomic medicine has been recently described [155].

NGS techniques are expected to generate new findings and indicate genetic alterations, which may be of help to better delineate the genes and biochemical pathways important for HGOS growth, progression, clinical behavior and, most of all, biomarkers that may predict which therapy will have the highest probability to obtain the major benefits with minimal risk of toxicity in genetically-stratified subgroups of patients.

Moreover, these methodological approaches may indicate new potential therapeutic targets, which could be taken into consideration to plan novel tailored treatment strategies aimed to improve outcome 
of patients with localized HGOS and, even more, of those with metastatic disease, for whom really effective therapeutic options are still limited.

Part of the aforementioned information is expected to derive from the Therapeutically Applicable Research to Generate Effective Treatments (TARGET) program (http://ocg.cancer.gov/programs/target/ projects/osteosarcoma; ClinicalTrials.gov Identifier: NCT01190943), a multicenter collaborative project aimed to the identification of genetic and epigenetic aberrations in HGOS through a combination of different genomic approaches. The objective of this study is to identify those aberrations that are involved in the pathogenesis of HGOS and which may play a role in chemoresistance and metastasis using high-resolution, genome-wide technologies. The final aim of the study is to indicate biomarkers to be validated as new therapeutic targets for patients with HGOS, especially for those with metastatic disease and/or unresponsive to standard chemotherapy.

The Individualized Therapy for Relapsed Malignancies in Childhood (INFORM) program (https://www.kitz-heidelberg.de/en/for-physicians/clinical-studies/molecular-diagnosticsstudies/inform/) [156] is another multicentric study that aims to identify novel therapeutic targets and to use them to drive clinical management of patients with pediatric malignant tumors, including HGOS [157].

The UK 100,000 Genomes Cancer Project (https://www.genomicsengland.co.uk/about-genomicsengland/the-100000-genomes-project/) [158] also plans to bring whole genome sequencing-provided evidence directly into clinical care in several rare diseases, as well as in advanced solid tumors and hematological malignancies [159].

The Geisinger MyCode Community Health Initiative (https://www.geisinger.org/mycode) [160] is a precision medicine project which is ongoing at Geisinger locations in Pennsylvania and New Jersey. One of the major objectives of this program is the establishment of a system-wide biobank designed to store blood and other samples from a large number of patients and participants (more than 190,000 patients/participants have already agreed and signed up to join this study). The final aim of this program is the use of DNA genomic analyses to improve healthcare through early diagnosis of different medical conditions and the indication of new treatments to manage each disease [161-163].

Very recently, the results of the Sarcoma Decision Impact Clinical Trial study have been published by the Foundation Medicine group [164]. This study applied the strategy of comprehensive genomic profiling to sequence both DNA and RNA from sarcoma tumor samples, with the aim to identify known and novel alterations that may drive oncogenicity and potentially impact on physicians' treatment decision-making. The authors assessed the feasibility of this approach in a larger group of 392 bone and soft-tissue sarcoma patients (including 16 patients with HGOS), showing that the success rate for bone tumor samples was $65.3 \%$.

In a subgroup of 28 patients with different malignancies, the impact of genomic profiling data on physicians' treatment decision-making was also assessed. Physicians decided to switch treatment on the basis of comprehensive genomic profiling in seven cases (25\%).

The first conclusion addressed by this study was that comprehensive genomic profiling can be applied to bone tumors, for which, however, careful sample acquisition with attention to decalcification and nucleic acid handling are mandatory to ensure usable results. The second main indication provided by this report was that comprehensive genomic profiling can impact on physician decision-making regarding treatment, in particular in relapsed patients.

\subsection{Epigenetics}

Epigenetic studies are also expected to provide information of possible clinical value in the near future. Research on non-coding RNAs in HGOS has been rapidly expanding and indicating miRNAs and lncRNAs, which might be considered as promising future candidate therapeutic targets $[133,134,165]$. Studies on polymorphisms of non-coding RNAs in HGOS are still at their beginning, but they are sure to increase in the next years. However, there are at least two major items that must be taken into consideration for a possible clinical translation of the provided evidence: 
1. It is mandatory to determine and validate the actual value of miRNAs and lncRNAs that have been highlighted in HGOS experimental models and clinical samples as possible therapeutic targets;

2. The design of non-coding RNA-based or targeted treatments with sufficient efficiency, delivery, therapeutic effects, and safety profiles to be transferred to the clinic is mostly still at a preclinical phase of development.

Targeting non-coding RNAs can be performed by using small interfering RNAs, antisense oligonucleotides, ribozymes, or aptamers, as well as by using clustered regularly interspaced palindromic repeats (CRISPR)/CRISPR-associated protein 9 (Cas9) methodologies $[133,165,166]$. Research in this field has been rapidly expanding and it will further enhance in the coming years. Therefore, there is hope that at least few of these approaches will be sufficiently developed and validated to be safely translated to the clinic in a medium-term period.

\subsection{Immunopharmacogenomics}

In addition to the aforementioned applications, NGS technologies have also been applied to the genetic characterization of the immune system inside a new field of research known as immunogenomics or immunopharmacogenomics [167]. Since host immune responses has been recognized to be important not only for immunotherapy efficacy, but also as mediators for cytotoxic agents and targeted drugs activity, immunopharmacogenomics will hopefully yield useful information to monitor tumor treatment response and predict clinical outcome. In addition, this approach may contribute to the identification of tumor neoantigens that may be proposed as novel immunotherapeutic targets.

By using NGS, it will also be possible to estimate the tumor mutational burden (TMB), which is an index of the number of mutations in a specific tumor genome. This possibility has a relevant clinical impact because it has been observed that higher numbers of somatic mutations are correlated with a better clinical response to monoclonal antibodies which block immune checkpoint molecules such as the CTLA-4, programmed cell death-1 (PD-1), and programmed death-ligand 1 (PD-L1) [168-170].

Despite the initial expectancies, immunotherapy has unfortunately not yet provided significant improvements in HGOS cure rate. These unsatisfactory results can be explained by the low TMB exhibited by the majority of HGOS patients [171,172]. Determining TMB with NGS, an approach which is already feasible in many laboratories and institutes, may therefore be of great help to identify those HGOS patients with a higher probability to respond to immunotherapy and drive the choice of the most appropriate immunotherapeutic approach on the basis of patients' genomic characteristics.

\subsection{Paired Sequencing}

A strategy that may speed up the identification of tumor-related biomarkers can also consist in paired sequencing of blood and tumor cells from the same patient, enabling the identification of the mutations and genetic alterations that are specifically acquired in the malignant cells but also those present at germline level.

Moreover, pharmacogenetic and pharmacogenomic information obtained from paired normal and tumor samples of the same patient will allow researchers to establish a direct relationship between the tumor genotype and a drug's efficacy, or between the constitutive genotype and the development of toxicity reactions. This body of evidence will be essential to modulate and optimize chemotherapy through the identification of the most responsive patients and those who have higher probabilities to develop treatment-related toxicities.

A fact that needs to be taken into consideration is that, since DNA is easily obtainable via a blood sample, saliva or buccal swab, the analysis of germline polymorphisms can routinely be applied to patients also during chemotherapy treatment, providing a predictive tool which may decrease the occurrence of adverse toxicities and increase drug efficacy and safety. 


\section{Conclusions}

The number of mutations or genetic alterations that can be considered as tumor drivers has significantly increased in the last decade thanks to the development of new techniques, as well as through the data generated by large international sequencing studies, such as the Cancer Genome Atlas [173] or the International Cancer Genome Consortium projects [174].

Several efforts are thus ongoing in HGOS preclinical and clinical research in order to identify genetic changes that can be used as biomarkers to predict tumor behavior, prognosis, drug response and toxicity development, which may enable early monitoring for recurrence of disease and, finally, be indicated as new candidate therapeutic targets. From this point of view, genome-wide technologies may be of great help for extracting genetic signatures that can be used as predictive biomarkers and identify patients eligible for specific targeted treatments [17].

Economical aspects have also to be considered. It is evident that pharmacogenetic and pharmacogenomic profiling has the potential to improve the treatment results in human tumors, as well as in other diseases. In this respect, the methods used in these studies must, however, be considered in cost-effectiveness evaluations of treatment driven by pharmacogenetic and pharmacogenomic biomarkers. The progressive decrease of the costs of the new technologies for genomic analysis is a positive trend that gives hope for the adoption of pharmacogenetic and pharmacogenomic profiling in clinical practice in the short-to-medium term.

Funding: The authors' studies and findings cited in this manuscript were supported by grants from the Foundation AIRC for Cancer Research (funding from AIRC under IG2014 - project ID.15851 and IG2018 - project ID.21487; P.I. Serra Massimo). SL has been supported by a fellowship of the Associazione Onlus "Il Pensatore - Matteo Amitrano".

Acknowledgments: We would like to dedicate this work in memory of Chiara Duse, Eleonora Betti, Matteo Amitrano, Aurora Tomaselli, Simone Dispensa, Gianmichele Modestino and Monica Morelli of whom families, relatives and friends support osteosarcoma research with their activities and donations. We would like to thank Cristina Ghinelli for the help in Figures editing.

Conflicts of Interest: The authors have no relevant affiliations or financial involvement with any organization or entity which may be in conflict with the subject matter or materials discussed in this review. These include employment, honoraria, stock ownership, royalties received or pending.

\section{Abbreviations}

$\begin{array}{ll}\text { ABC } & \text { ATP-binding cassette } \\ \text { ABCB1 } & \text { ATP-binding cassette, subfamily B (MDR/TAP), member 1 } \\ \text { ABCC2 } & \text { ATP-binding cassette, subfamily C (CFTR/MRP), member 2 } \\ \text { ABCC3 } & \text { ATP-binding cassette, subfamily C (CFTR/MRP), member 3 } \\ \text { ABCC5 } & \text { ATP-binding cassette, subfamily C (CFTR/MRP), member } 5 \\ \text { ACT } & \text { anthracycline-induced cardiotoxicity } \\ \text { ACYP2 } & \text { acylphosphatase 2 } \\ \text { ADME } & \text { absorption, distribution, metabolism, excretion } \\ \text { AKT } & \text { AKT serine/threonine kinase } \\ \text { ALT } & \text { alanine transaminase } \\ \text { ATM } & \text { ataxia telangiectasia mutated) } \\ \text { ATR } & \text { ataxia telangiectasia and Rad3 related } \\ \text { ATRX } & \text { ATRX chromatin remodeler } \\ \text { AURKB } & \text { Aurora kinase B } \\ \text { B-Raf } & \text { B-Raf proto-oncogene, serine/threonine kinase } \\ \text { BRCA1 } & \text { breast related cancer antigen 1 } \\ \text { BRCA 2 } & \text { breast related cancer antigen 2 } \\ \text { Cas9 } & \text { CRISPR associated protein 9 } \\ \text { CBRs } & \text { carbonyl reductases } \\ \text { CCNE1 } & \text { cyclin E1 } \\ \text { CDK4 } & \text { cyclin-dependent kinase 4 }\end{array}$




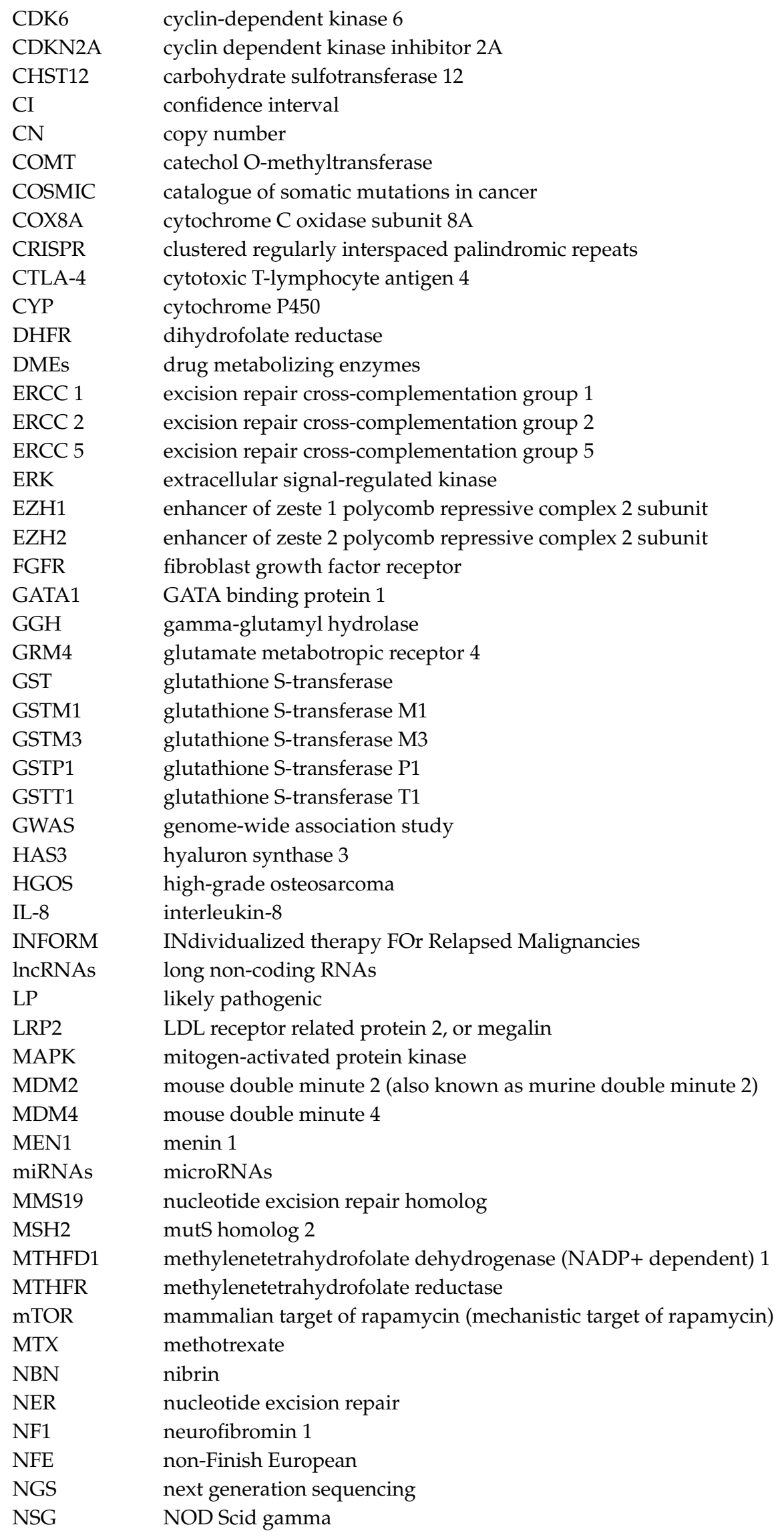




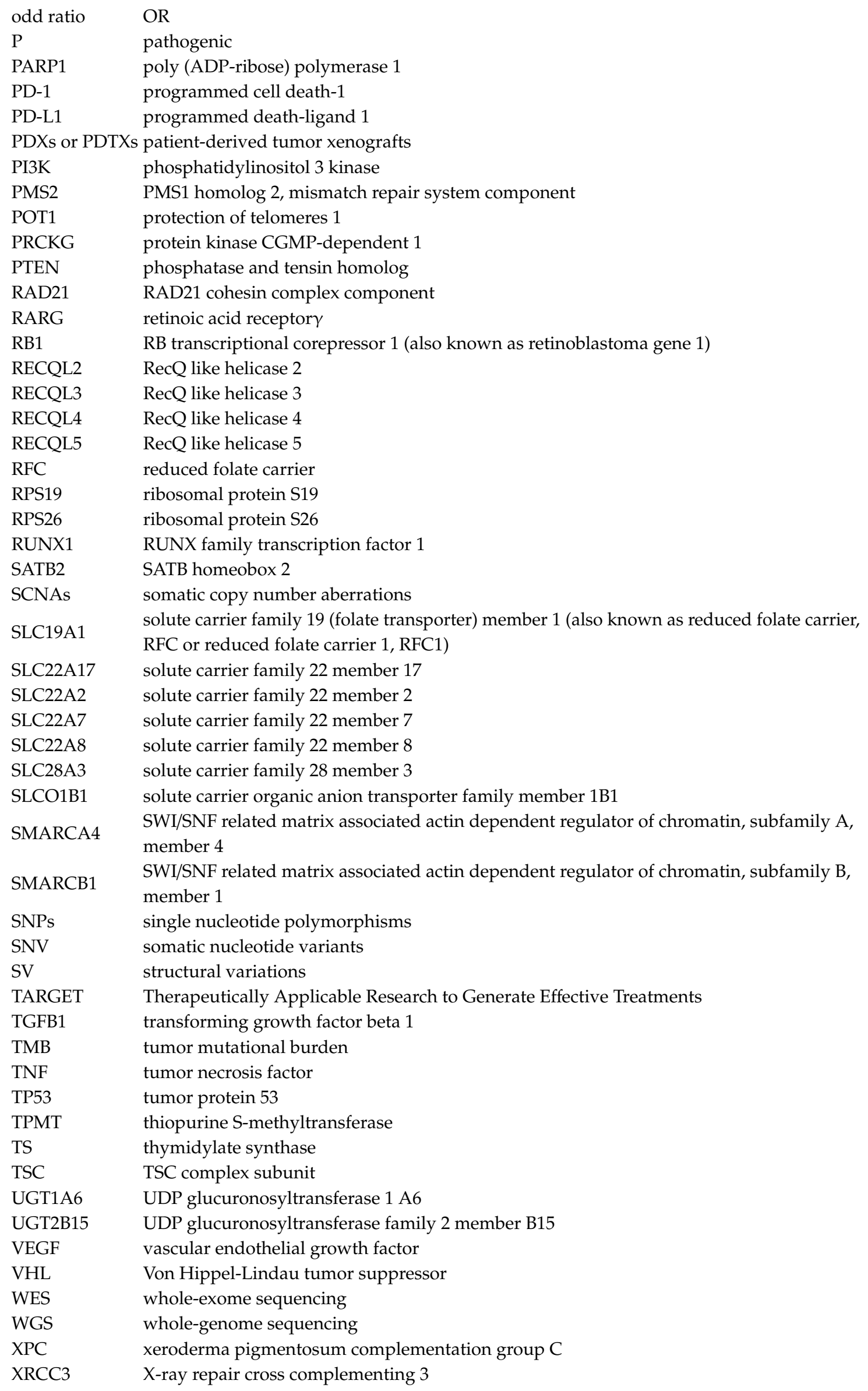




\section{References}

1. Mirabello, L.; Troisi, R.J.; Savage, S.A. Osteosarcoma incidence and survival rates from 1973 to 2004. Cancer 2009, 115, 1531-1543. [CrossRef]

2. Picci, P. Osteosarcoma. In Diagnosis of Musculoskeletal Tumors and Tumor-Like Conditions, 2nd ed.; Picci, P., Manfrini, M., Donati, D., Gambarotti, M., Righi, A., Vanel, D., Dei Tos, A., Eds.; Springer Nature Switzerland AG: Cham, Switzerland, 2020; pp. 185-212.

3. Whelan, J.S.; Davis, L.E. Osteosarcoma, Chondrosarcoma, and Chordoma. J. Clin. Oncol. 2018, 36, $188-193$. [CrossRef] [PubMed]

4. Harrison, D.J.; Geller, D.S.; Gill, J.; Lewis, V.O.; Gorlick, R. Current and future therapeutic approaches for osteosarcoma. Expert Rev. Anticancer. Ther. 2017, 18, 39-50. [CrossRef] [PubMed]

5. Kager, L.; Tamamyan, G.; Bielack, S. Novel insights and therapeutic interventions for pediatric osteosarcoma. Futur. Oncol. 2017, 13, 357-368. [CrossRef]

6. Simpson, E.; Brown, H.L. Understanding osteosarcomas. J. Am. Acad. Physician Assist. 2018, 31, 15-19. [CrossRef]

7. Ferrari, S.; Serra, M. An update on chemotherapy for osteosarcoma. Expert Opin. Pharmacother. 2015, 16, 2727-2736. [CrossRef] [PubMed]

8. Smeland, S.; Bielack, S.S.; Whelan, J.; Bernstein, M.; Hogendoorn, P.C.W.; Krailo, M.D.; Gorlick, R.; Janeway, K.A.; Ingleby, F.C.; Anninga, J.; et al. Survival and prognosis with osteosarcoma: Outcomes in more than 2000 patients in the EURAMOS-1 (European and American Osteosarcoma Study) cohort. Eur. J. Cancer 2019, 109, 36-50. [CrossRef]

9. Hattinger, C.M.; Vella, S.; Tavanti, E.; Fanelli, M.; Picci, P.; Serra, M. Pharmacogenomics of second-line drugs used for treatment of unresponsive or relapsed osteosarcoma patients. Pharmacogenomics 2016, 17, 2097-2114. [CrossRef]

10. Roden, D.M.; McLeod, H.L.; Relling, M.V.; Williams, M.S.; Mensah, G.A.; Peterson, J.F.; Van Driest, S.L. Pharmacogenomics. Lancet 2019, 394, 521-532. [CrossRef]

11. Serra, M.; Hattinger, C.M. The pharmacogenomics of osteosarcoma. Pharm. J. 2017, 17, 11-20. [CrossRef]

12. Evans, W.E.; Relling, M.V. Pharmacogenomics: Translating Functional Genomics into Rational Therapeutics. Science 1999, 286, 487-491. [CrossRef] [PubMed]

13. Weng, L.; Zhang, L.; Peng, Y.; Huang, R.S. Pharmacogenetics and pharmacogenomics: A bridge to individualized cancer therapy. Pharmacogenomics 2013, 14, 315-324. [CrossRef] [PubMed]

14. Gianferante, D.M.; Mirabello, L.; Savage, S.A. Germline and somatic genetics of osteosarcoma-Connecting aetiology, biology and therapy. Nat. Rev. Endocrinol. 2017, 13, 480-491. [CrossRef] [PubMed]

15. Mirabello, L.; Macari, E.R.; Jessop, L.; Ellis, S.R.; Myers, T.; Giri, N.; Taylor, A.M.; McGrath, K.E.; Humphries, J.M.; Ballew, B.J.; et al. Whole-exome sequencing and functional studies identify RPS29 as a novel gene mutated in multicase Diamond-Blackfan anemia families. Blood 2014, 124, 24-32. [CrossRef]

16. Ulirsch, J.C.; Verboon, J.M.; Kazerounian, S.; Guo, M.H.; Yuan, D.; Ludwig, L.S.; Handsaker, R.E.; Abdulhay, N.J.; Fiorini, C.; Genovese, G.; et al. The Genetic Landscape of Diamond-Blackfan Anemia. Am. J. Hum. Genet. 2018, 103, 930-947. [CrossRef]

17. Rickel, K.; Fang, F.; Tao, J. Molecular genetics of osteosarcoma. Bone 2016, 102, 69-79. [CrossRef]

18. Mai, P.L.; Best, A.F.; Peters, J.A.; DeCastro, R.M.; Khincha, P.P.; Loud, J.T.; Bremer, R.C.; Rosenberg, P.S.; Savage, S.A. Risks of first and subsequent cancers among TP53 mutation carriers in the National Cancer Institute Li-Fraumeni syndrome cohort. Cancer 2016, 122, 3673-3681. [CrossRef]

19. Hameed, M.; Mandelker, D. Tumor Syndromes Predisposing to Osteosarcoma. Adv. Anat. Pathol. 2018, 25, 217-222. [CrossRef]

20. Wang, L.L.; Levy, M.L.; Lewis, R.A.; Chintagumpala, M.M.; Lev, R.; Rogers, M.; Plon, S.E. Clinical manifestations in a cohort of 41 Rothmund-Thomson syndrome patients. Am. J. Med. Genet. 2001, 102, 11-17. [CrossRef]

21. Siitonen, H.A.; Sotkasiira, J.; Biervliet, M.; Benmansour, A.; Capri, Y.; Cormier-Daire, V.; Crandall, B.; Hannula-Jouppi, K.; Hennekam, R.; Herzog, D.; et al. The mutation spectrum in RECQL4 diseases. Eur. J. Hum. Genet. 2008, 17, 151-158. [CrossRef] 
22. Calvert, G.T.; Randall, R.L.; Jones, K.B.; Cannon-Albright, L.A.; Lessnick, S.; Schiffman, J.D. At-Risk Populations for Osteosarcoma: The Syndromes and Beyond. Sarcoma 2012, 2012, 1-9. [CrossRef] [PubMed]

23. Lipton, J.M.; Federman, N.; Khabbaze, Y.; Schwartz, C.L.; Hilliard, L.M.; Clark, J.I.; Vlachos, A. Osteogenic Sarcoma Associated with Diamond-Blackfan Anemia: A Report From the Diamond-Blackfan Anemia Registry. J. Pediatr. Hematol. 2001, 23, 39-44. [CrossRef] [PubMed]

24. Vlachos, A.; Rosenberg, P.S.; Atsidaftos, E.; Kang, J.; Onel, K.; Sharaf, R.N.; Alter, B.P.; Lipton, J.M. Increased risk of colon cancer and osteogenic sarcoma in Diamond-Blackfan anemia. Blood 2018, 132, 2205-2208. [CrossRef] [PubMed]

25. Flanagan, M.; Cunniff, C.M. Bloom Syndrome. In GeneReviews; University of Washington: Seattle, WA, USA, 2006; pp. 1993-2020.

26. Yu, W.; Clyne, M.; Khoury, M.J.; Gwinn, M. Phenopedia and Genopedia: Disease-centered and gene-centered views of the evolving knowledge of human genetic associations. Bioinformatics 2009, 26, 145-146. [CrossRef] [PubMed]

27. Mirabello, L.; Yu, K.; Berndt, S.I.; Burdette, L.; Wang, Z.; Chowdhury, S.; Teshome, K.; Uzoka, A.; Hutchinson, A.; Grotmol, T.; et al. A comprehensive candidate gene approach identifies genetic variation associated with osteosarcoma. BMC Cancer 2011, 11, 209. [CrossRef] [PubMed]

28. Savage, S.A.; Mirabello, L.; Wang, Z.; Gastier-Foster, J.M.; Gorlick, R.; Khanna, C.; Flanagan, A.M.; Tirabosco, R.; Andrulis, I.L.; Wunder, J.S.; et al. Genome-wide association study identifies two susceptibility loci for osteosarcoma. Nat. Genet. 2013, 45, 799-803. [CrossRef]

29. Jiang, C.; Chen, H.; Shao, L.; Dong, Y. GRM4 gene polymorphism is associated with susceptibility and prognosis of osteosarcoma in a Chinese Han population. Med. Oncol. 2014, 31, 50. [CrossRef]

30. Wang, K.; Zhao, J.; He, M.; Fowdur, M.; Jiang, T.; Luo, S. Association of GRM4 gene polymorphisms with susceptibility and clinicopathological characteristics of osteosarcoma in Guangxi Chinese population. Tumour Biol. 2016, 37, 1105-1112. [CrossRef]

31. Yang, Y.; Basu, S.; Mirabello, L.; Spector, L.; Zhang, L. A Bayesian Gene-Based Genome-Wide Association Study Analysis of Osteosarcoma Trio Data Using a Hierarchically Structured Prior. Cancer Inform. 2018, 17, 1176935118775103. [CrossRef]

32. Mirabello, L.; Yeager, M.; Mai, P.L.; Gastier-Foster, J.M.; Gorlick, R.; Khanna, C.; Patino-Garcia, A.; Sierrasesumaga, L.; Lecanda, F.; Andrulis, I.L.; et al. Germline TP53 variants and susceptibility to osteosarcoma. J. Natl. Cancer Inst. 2015, 107, djv101. [CrossRef]

33. Ballinger, M.L.; Goode, D.L.; Ray-Coquard, I.; James, P.A.; Mitchell, G.; Niedermayr, E.; Puri, A.; Schiffman, J.D.; Dite, G.S.; Cipponi, A.; et al. Monogenic and polygenic determinants of sarcoma risk: An international genetic study. Lancet Oncol. 2016, 17, 1261-1271. [CrossRef]

34. Grobner, S.N.; Worst, B.C.; Weischenfeldt, J.; Buchhalter, I.; Kleinheinz, K.; Rudneva, V.A.; Johann, P.D.; Balasubramanian, G.P.; Segura-Wang, M.; Brabetz, S.; et al. The landscape of genomic alterations across childhood cancers. Nature 2018, 555, 321-327. [CrossRef] [PubMed]

35. Zhang, J.; Walsh, M.F.; Wu, G.; Edmonson, M.N.; Gruber, T.A.; Easton, J.; Hedges, D.; Ma, X.; Zhou, X.; Yergeau, D.A.; et al. Germline Mutations in Predisposition Genes in Pediatric Cancer. N. Engl. J. Med. 2015, 373, 2336-2346. [CrossRef] [PubMed]

36. Mirabello, L.; Zhu, B.; Koster, R.; Karlins, E.; Dean, M.; Yeager, M.; Gianferante, M.; Spector, L.G.; Morton, L.M.; Karyadi, D.; et al. Frequency of Pathogenic Germline Variants in Cancer-Susceptibility Genes in Patients With Osteosarcoma. JAMA Oncol. 2020. [CrossRef] [PubMed]

37. Huang, X.; Wu, F.; Zhang, Z.; Shao, Z. Association between TP53 rs1042522 gene polymorphism and the risk of malignant bone tumors: A meta-analysis. Biosci. Rep. 2019, 39, BSR20181832. [CrossRef]

38. Moghimi, M.; Sobhan, M.R.; Jarahzadeh, M.H.; Morovati-Sharifabad, M.; Aghili, K.; Ahrar, H.; Zare-Shehneh, M.; Neamatzadeh, H. Association of GSTM1, GSTT1, GSTM3, and GSTP1 Genes Polymorphisms with Susceptibility to Osteosarcoma: A Case-Control Study and Meta-Analysis. Asian Pac. J. Cancer Prev. 2019, 20, 675-682. [CrossRef]

39. Ito, M.; Barys, L.; O’Reilly, T.; Young, S.; Gorbatcheva, B.; Monahan, J.; Zumstein-Mecker, S.; Choong, P.F.; Dickinson, I.; Crowe, P.; et al. Comprehensive mapping of p53 pathway alterations reveals an apparent role for both SNP309 and MDM2 amplification in sarcomagenesis. Clin. Cancer Res. 2011, 17, 416-426. [CrossRef] 
40. Toffoli, G.; Biason, P.; Russo, A.; De Mattia, E.; Cecchin, E.; Hattinger, C.M.; Pasello, M.; Alberghini, M.; Ferrari, C.; Scotlandi, K.; et al. Effect of TP53 Arg72Pro and MDM2 SNP309 polymorphisms on the risk of high-grade osteosarcoma development and survival. Clin. Cancer Res. 2009, 15, 3550-3556. [CrossRef]

41. Wang, L.; Liu, Z.; Jing, P.; Shao, L.; Chen, L.; He, X.; Gong, W. Effects of murine double minute 2 polymorphisms on the risk and survival of osteosarcoma: A systemic review and meta-analysis. Tumour Biol. 2014, 35, 1649-1652. [CrossRef]

42. Bilbao-Aldaiturriaga, N.; Askaiturrieta, Z.; Granado-Tajada, I.; Goricar, K.; Dolzan, V.; For The Slovenian Osteosarcoma Study, G.; Garcia-Miguel, P.; Garcia de Andoin, N.; Martin-Guerrero, I.; Garcia-Orad, A. A systematic review and meta-analysis of MDM2 polymorphisms in osteosarcoma susceptibility. Pediatr. Res. 2016, 80, 472-479. [CrossRef]

43. Wang, X.; Liu, Z. Systematic meta-analysis of genetic variants associated with osteosarcoma susceptibility. Medicine (Baltimore) 2018, 97, e12525. [CrossRef] [PubMed]

44. Ognjanovic, S.; Olivier, M.; Bergemann, T.L.; Hainaut, P. Sarcomas in TP53 germline mutation carriers: A review of the IARC TP53 database. Cancer 2012, 118, 1387-1396. [CrossRef] [PubMed]

45. Pakos, E.E.; Kyzas, P.A.; Ioannidis, J.P. Prognostic significance of TP53 tumor suppressor gene expression and mutations in human osteosarcoma: A meta-analysis. Clin. Cancer Res. 2004, 10, 6208-6214. [CrossRef] [PubMed]

46. Thoenen, E.; Curl, A.; Iwakuma, T. TP53 in bone and soft tissue sarcomas. Pharmacol. Ther. 2019, 202, $149-164$. [CrossRef]

47. Overholtzer, M.; Rao, P.H.; Favis, R.; Lu, X.Y.; Elowitz, M.B.; Barany, F.; Ladanyi, M.; Gorlick, R.; Levine, A.J. The presence of p53 mutations in human osteosarcomas correlates with high levels of genomic instability. Proc. Natl. Acad. Sci. USA 2003, 100, 11547-11552. [CrossRef]

48. Haupt, S.; Mejia-Hernandez, J.O.; Vijayakumaran, R.; Keam, S.P.; Haupt, Y. The long and the short of it: The MDM4 tail so far. J. Mol. Cell Biol. 2019, 11, 231-244. [CrossRef]

49. Duhamel, L.A.; Ye, H.; Halai, D.; Idowu, B.D.; Presneau, N.; Tirabosco, R.; Flanagan, A.M. Frequency of Mouse Double Minute 2 (MDM2) and Mouse Double Minute 4 (MDM4) amplification in parosteal and conventional osteosarcoma subtypes. Histopathology 2012, 60, 357-359. [CrossRef]

50. Dewaele, M.; Tabaglio, T.; Willekens, K.; Bezzi, M.; Teo, S.X.; Low, D.H.; Koh, C.M.; Rambow, F.; Fiers, M.; Rogiers, A.; et al. Antisense oligonucleotide-mediated MDM4 exon 6 skipping impairs tumor growth. J. Clin. Investig. 2016, 126, 68-84. [CrossRef]

51. Lenos, K.; Grawenda, A.M.; Lodder, K.; Kuijjer, M.L.; Teunisse, A.F.; Repapi, E.; Grochola, L.F.; Bartel, F.; Hogendoorn, P.C.; Wuerl, P.; et al. Alternate splicing of the p53 inhibitor HDMX offers a superior prognostic biomarker than p53 mutation in human cancer. Cancer Res. 2012, 72, 4074-4084. [CrossRef]

52. Lenos, K.; Jochemsen, A.G. Functions of MDMX in the modulation of the p53-response. J. Biomed. Biotechnol. 2011, 2011, 876173. [CrossRef]

53. Cai, X.; Yang, M. The functional MDM2 T309G genetic variant but not P53 Arg72Pro polymorphism is associated with risk of sarcomas: A meta-analysis. J. Cancer Res. Clin. Oncol. 2012, 138, 555-561. [CrossRef] [PubMed]

54. Hattinger, C.M.; Biason, P.; Iacoboni, E.; Gagno, S.; Fanelli, M.; Tavanti, E.; Vella, S.; Ferrari, S.; Roli, A.; Roncato, R.; et al. Candidate germline polymorphisms of genes belonging to the pathways of four drugs used in osteosarcoma standard chemotherapy associated with risk, survival and toxicity in non-metastatic high-grade osteosarcoma. Oncotarget 2016, 7, 61970-61987. [CrossRef]

55. Savage, S.A.; Burdett, L.; Troisi, R.; Douglass, C.; Hoover, R.N.; Chanock, S.J. Germ-line genetic variation of TP53 in osteosarcoma. Pediatr. Blood Cancer 2007, 49, 28-33. [CrossRef] [PubMed]

56. Ru, J.Y.; Cong, Y.; Kang, W.B.; Yu, L.; Guo, T.; Zhao, J.N. Polymorphisms in TP53 are associated with risk and survival of osteosarcoma in a Chinese population. Int. J. Clin. Exp. Pathol. 2015, 8, 3198-3203. [PubMed]

57. Madhusudan, S.; Middleton, M.R. The emerging role of DNA repair proteins as predictive, prognostic and therapeutic targets in cancer. Cancer Treat. Rev. 2005, 31, 603-617. [CrossRef]

58. Torgovnick, A.; Schumacher, B. DNA repair mechanisms in cancer development and therapy. Front. Genet. 2015, 6, 157. [CrossRef] [PubMed] 
59. Lieberman, H.B. DNA damage repair and response proteins as targets for cancer therapy. Curr. Med. Chem. 2008, 15, 360-367. [CrossRef]

60. Cao, Z.H.; Yin, H.P.; Jiang, N.; Yu, B. Association between ERCC1 and ERCC2 gene polymorphisms and chemotherapy response and overall survival in osteosarcoma. Genet. Mol. Res. 2015, 14, 10145-10151. [CrossRef]

61. Ji, W.P.; He, N.B. Investigation on the DNA repaired gene polymorphisms and response to chemotherapy and overall survival of osteosarcoma. Int. J. Clin. Exp. Pathol. 2015, 8, 894-899.

62. Sun, Y.; Wu, Y.; Li, W.; Kong, Z.; Zou, X. Genetic polymorphisms in nucleotide excision repair pathway influences response to chemotherapy and overall survival in osteosarcoma. Int. J. Clin. Exp. Pathol. 2015, 8, 7905-7912.

63. Zhang, H.; Ge, J.; Hong, H.; Bi, L.; Sun, Z. Genetic polymorphisms in ERCC1 and ERCC2 genes are associated with response to chemotherapy in osteosarcoma patients among Chinese population: A meta-analysis. World J. Surg. Oncol. 2017, 15, 75. [CrossRef]

64. Zhang, Q.; Lv, L.Y.; Li, B.J.; Zhang, J.; Wei, F. Investigation of ERCC1 and ERCC2 gene polymorphisms and response to chemotherapy and overall survival in osteosarcoma. Genet. Mol. Res. 2015, 14, 11235-11241. [CrossRef] [PubMed]

65. Hao, T.; Feng, W.; Zhang, J.; Sun, Y.J.; Wang, G. Association of four ERCC1 and ERCC2 SNPs with survival of bone tumour patients. Asian Pac. J. Cancer Prev. 2012, 13, 3821-3824. [CrossRef]

66. Wang, M.J.; Zhu, Y.; Guo, X.J.; Tian, Z.Z. Genetic variability of genes involved in DNA repair influence treatment outcome in osteosarcoma. Genet. Mol. Res. 2015, 14, 11652-11657. [CrossRef] [PubMed]

67. Obiedat, H.; Alrabadi, N.; Sultan, E.; Al Shatti, M.; Zihlif, M. The effect of ERCC1 and ERCC2 gene polymorphysims on response to cisplatin based therapy in osteosarcoma patients. BMC Med. Genet. 2018, 19, 112. [CrossRef] [PubMed]

68. Caronia, D.; Patino-Garcia, A.; Milne, R.L.; Zalacain-Diez, M.; Pita, G.; Alonso, M.R.; Moreno, L.T.; Sierrasesumaga-Ariznabarreta, L.; Benitez, J.; Gonzalez-Neira, A. Common variations in ERCC2 are associated with response to cisplatin chemotherapy and clinical outcome in osteosarcoma patients. Pharmacogn J. 2009, 9, 347-353. [CrossRef]

69. Biason, P.; Hattinger, C.M.; Innocenti, F.; Talamini, R.; Alberghini, M.; Scotlandi, K.; Zanusso, C.; Serra, M.; Toffoli, G. Nucleotide excision repair gene variants and association with survival in osteosarcoma patients treated with neoadjuvant chemotherapy. Pharmacogn. J. 2012, 12, 476-483. [CrossRef]

70. Li, J.; Liu, S.; Wang, W.; Zhang, K.; Liu, Z.; Zhang, C.; Chen, S.; Wu, S. ERCC polymorphisms and prognosis of patients with osteosarcoma. Tumour Biol. 2014, 35, 10129-10136. [CrossRef]

71. Yang, L.M.; Li, X.H.; Bao, C.F. Glutathione S-transferase P1 and DNA polymorphisms influence response to chemotherapy and prognosis of bone tumors. Asian Pac. J. Cancer Prev. 2012, 13, 5883-5886. [CrossRef]

72. Goricar, K.; Kovac, V.; Jazbec, J.; Zakotnik, B.; Lamovec, J.; Dolzan, V. Genetic variability of DNA repair mechanisms and glutathione-S-transferase genes influences treatment outcome in osteosarcoma. Cancer Epidemiol. 2015, 39, 182-188. [CrossRef]

73. Liu, Z.F.; Asila, A.L.; Aikenmu, K.; Zhao, J.; Meng, Q.C.; Fang, R. Influence of ERCC2 gene polymorphisms on the treatment outcome of osteosarcoma. Genet. Mol. Res. 2015, 14, 12967-12972. [CrossRef] [PubMed]

74. Bai, S.B.; Chen, H.X.; Bao, Y.X.; Luo, X.; Zhong, J.J. Predictive impact of common variations in DNA repair genes on clinical outcome of osteosarcoma. Asian Pac. J. Cancer Prev. 2013, 14, 3677-3680. [CrossRef] [PubMed]

75. Sun, X.H.; Hou, W.G.; Zhao, H.X.; Zhao, Y.L.; Ma, C.; Liu, Y. Single nucleotide polymorphisms in the NER pathway and clinical outcome of patients with bone malignant tumors. Asian Pac. J. Cancer Prev. 2013, 14, 2049-2052. [CrossRef] [PubMed]

76. Zhao, Y.L.; Yang, L.B.; Geng, X.L.; Zhou, Q.L.; Qin, H.; Yang, L.; Dong, Y.Z.; Zhong, J.J. The association of XPG and MMS19L polymorphisms response to chemotherapy in osteosarcoma. Pak. J. Med. Sci. 2013, 29, 1225-1229. [CrossRef]

77. Hagleitner, M.M.; Coenen, M.J.; Gelderblom, H.; Makkinje, R.R.; Vos, H.I.; de Bont, E.S.; van der Graaf, W.T.; Schreuder, H.B.; Flucke, U.E.; van Leeuwen, F.N.; et al. A first step towards personalized medicine in osteosarcoma: Pharmacogenetics as predictive marker of outcome after chemotherapy based treatment. Clin. Cancer Res. 2015, 21, 3436-3441. [CrossRef] 
78. Liu, X.; Zhang, Z.; Deng, C.; Tian, Y.; Ma, X. Meta-analysis showing that ERCC1 polymorphism is predictive of osteosarcoma prognosis. Oncotarget 2017, 8, 62769-62779. [CrossRef]

79. Michael, M.; Doherty, M.M. Tumoral drug metabolism: Overview and its implications for cancer therapy. J. Clin. Oncol. 2005, 23, 205-229. [CrossRef]

80. Hayes, J.D.; Flanagan, J.U.; Jowsey, I.R. Glutathione transferases. Annu Rev. Pharmacol. Toxicol. 2005, 45, 51-88. [CrossRef]

81. Lo, H.W.; Ali-Osman, F. Genetic polymorphism and function of glutathione S-transferases in tumor drug resistance. Curr. Opin. Pharmacol. 2007, 7, 367-374. [CrossRef]

82. Li, J.Z.; Tian, Z.Q.; Jiang, S.N.; Feng, T. Effect of variation of ABCB1 and GSTP1 on osteosarcoma survival after chemotherapy. Genet. Mol. Res. 2014, 13, 3186-3192. [CrossRef]

83. Liu, S.; Yi, Z.; Ling, M.; Shi, J.; Qiu, Y.; Yang, S. Predictive potential of ABCB1, ABCC3, and GSTP1 gene polymorphisms on osteosarcoma survival after chemotherapy. Tumour Biol. 2014, 35, 9897-9904. [CrossRef] [PubMed]

84. Teng, J.W.; Yang, Z.M.; Li, J.; Xu, B. Predictive role of Glutathione S-transferases (GSTs) on the prognosis of osteosarcoma patients treated with chemotherapy. Pak. J. Med. Sci. 2013, 29, 1182-1186. [CrossRef] [PubMed]

85. Windsor, R.E.; Strauss, S.J.; Kallis, C.; Wood, N.E.; Whelan, J.S. Germline genetic polymorphisms may influence chemotherapy response and disease outcome in osteosarcoma: A pilot study. Cancer 2012, 118, 1856-1867. [CrossRef]

86. Zhang, S.L.; Mao, N.F.; Sun, J.Y.; Shi, Z.C.; Wang, B.; Sun, Y.J. Predictive potential of glutathione S-transferase polymorphisms for prognosis of osteosarcoma patients on chemotherapy. Asian Pac. J. Cancer Prev. 2012, 13, 2705-2709. [CrossRef] [PubMed]

87. Salinas-Souza, C.; Petrilli, A.S.; de Toledo, S.R. Glutathione S-transferase polymorphisms in osteosarcoma patients. Pharm. Genom. 2010, 20, 507-515. [CrossRef] [PubMed]

88. Barnette, P.; Scholl, R.; Blandford, M.; Ballard, L.; Tsodikov, A.; Magee, J.; Williams, S.; Robertson, M.; Ali-Osman, F.; Lemons, R.; et al. High-throughput detection of glutathione s-transferase polymorphic alleles in a pediatric cancer population. Cancer Epidemiol. Biomark. Prev. 2004, 13, 304-313. [CrossRef]

89. Pu, F.; Chen, F.; Chen, S.; Wang, B.; Liu, J.; Shao, Z. Association between GSTP1 polymorphisms and prognosis of osteosarcoma in patients treated with chemotherapy: A meta-analysis. Onco Targets Ther. 2015, 8, 1835-1842.

90. Wang, Z.; Xu, H.; He, M.; Wu, H.; Zhu, Y.; Su, Z. The association of glutathione S-transferase polymorphisms in patients with osteosarcoma: Evidence from a meta-analysis. Eur. J. Cancer Care (Engl.) 2015, 24, 417-424. [CrossRef]

91. Lan, J.; Yang, Q.; Zhou, M.; Xu, R.; Zhou, C.; Wang, J.; Zheng, H. A meta-analysis of association between glutathione S-transferase gene polymorphism and osteosarcoma chemosensitivity in Chinese population. J. Cancer Res. Ther. 2016, 12, 64-67.

92. McFadyen, M.C.; Melvin, W.T.; Murray, G.I. Cytochrome P450 enzymes: Novel options for cancer therapeutics. Mol. Cancer Ther. 2004, 3, 363-371.

93. Caronia, D.; Patino-Garcia, A.; Perez-Martinez, A.; Pita, G.; Moreno, L.T.; Zalacain-Diez, M.; Molina, B.; Colmenero, I.; Sierrasesumaga, L.; Benitez, J.; et al. Effect of ABCB1 and ABCC3 polymorphisms on osteosarcoma survival after chemotherapy: A pharmacogenetic study. PLoS ONE 2011, 6, e26091. [CrossRef]

94. Sun, X.; Li, A.; Geng, X.; Liu, Y.; Zhao, H.; Zhao, Y. Effect of ABCB1 polymorphism on the clinical outcome of osteosarcoma patients after receiving chemotherapy. Pak. J. Med. Sci. 2014, 30, 886-890. [CrossRef] [PubMed]

95. Yang, J.; Wang, Z.G.; Cai, H.Q.; Li, Y.C.; Xu, Y.L. Effect of variation of ABCB1 and ABCC3 genotypes on the survival of bone tumor cases after chemotherapy. Asian Pac. J. Cancer Prev. 2013, 14, 4595-4598. [CrossRef]

96. Chen, X.; Jiang, M.; Zhao, R.K.; Gu, G.H. Quantitative Assessment of the Association between ABC Polymorphisms and Osteosarcoma Response: A Meta-analysis. Asian Pac. J. Cancer Prev 2015, 16, 4659-4664. [CrossRef] [PubMed]

97. Duffaud, F.; Egerer, G.; Ferrari, S.; Rassam, H.; Boecker, U.; Bui-Nguyen, B. A phase II trial of second-line pemetrexed in adults with advanced/metastatic osteosarcoma. Eur. J. Cancer 2012, 48, 564-570. [CrossRef] [PubMed]

98. O’Day, K.; Gorlick, R. Novel therapeutic agents for osteosarcoma. Expert Rev. Anticancer Ther. 2009, 9, 511-523. [CrossRef] 
99. Warwick, A.B.; Malempati, S.; Krailo, M.; Melemed, A.; Gorlick, R.; Ames, M.M.; Safgren, S.L.; Adamson, P.C.; Blaney, S.M. Phase 2 trial of pemetrexed in children and adolescents with refractory solid tumors: A Children's Oncology Group study. Pediatr. Blood Cancer 2013, 60, 237-241. [CrossRef]

100. Jabeen, S.; Holmboe, L.; Alnaes, G.I.; Andersen, A.M.; Hall, K.S.; Kristensen, V.N. Impact of genetic variants of RFC1, DHFR and MTHFR in osteosarcoma patients treated with high-dose methotrexate. Pharmacogn. J. 2015, 15, 385-390. [CrossRef]

101. Goricar, K.; Kovac, V.; Jazbec, J.; Zakotnik, B.; Lamovec, J.; Dolzan, V. Influence of the folate pathway and transporter polymorphisms on methotrexate treatment outcome in osteosarcoma. Pharmacogn. Genom. 2014, 24, 514-521. [CrossRef]

102. Janeway, K.A.; Grier, H.E. Sequelae of osteosarcoma medical therapy: A review of rare acute toxicities and late effects. Lancet Oncol. 2010, 11, 670-678. [CrossRef]

103. Vos, H.I.; Coenen, M.J.; Guchelaar, H.J.; Te Loo, D.M. The role of pharmacogenetics in the treatment of osteosarcoma. Drug Discov. Today 2016, 21, 1775-1786. [CrossRef] [PubMed]

104. Aminkeng, F.; Ross, C.J.; Rassekh, S.R.; Hwang, S.; Rieder, M.J.; Bhavsar, A.P.; Smith, A.; Sanatani, S.; Gelmon, K.A.; Bernstein, D.; et al. Recommendations for genetic testing to reduce the incidence of anthracycline-induced cardiotoxicity. Br. J. Clin. Pharmacol. 2016, 82, 683-695. [CrossRef] [PubMed]

105. Lee, J.W.; Pussegoda, K.; Rassekh, S.R.; Monzon, J.G.; Liu, G.; Hwang, S.; Bhavsar, A.P.; Pritchard, S.; Ross, C.J.; Amstutz, U.; et al. Clinical Practice Recommendations for the Management and Prevention of Cisplatin-Induced Hearing Loss Using Pharmacogenetic Markers. Ther. Drug Monit. 2016, 38, 423-431. [CrossRef] [PubMed]

106. Hattinger, C.M.; Tavanti, E.; Fanelli, M.; Vella, S.; Picci, P.; Serra, M. Pharmacogenomics of genes involved in antifolate drug response and toxicity in osteosarcoma. Expert Opin. Drug Metab. Toxicol. 2017, 13, 245-257. [CrossRef] [PubMed]

107. Patino-Garcia, A.; Zalacain, M.; Marrodan, L.; San-Julian, M.; Sierrasesumaga, L. Methotrexate in pediatric osteosarcoma: Response and toxicity in relation to genetic polymorphisms and dihydrofolate reductase and reduced folate carrier 1 expression. J. Pediatr. 2009, 154, 688-693. [CrossRef]

108. Xie, L.; Guo, W.; Yang, Y.; Ji, T.; Xu, J. More severe toxicity of genetic polymorphisms on MTHFR activity in osteosarcoma patients treated with high-dose methotrexate. Oncotarget 2018, 9, 11465-11476. [CrossRef]

109. Hegyi, M.; Arany, A.; Semsei, A.F.; Csordas, K.; Eipel, O.; Gezsi, A.; Kutszegi, N.; Csoka, M.; Muller, J.; Erdelyi, D.J.; et al. Pharmacogenetic analysis of high-dose methotrexate treatment in children with osteosarcoma. Oncotarget 2017, 8, 9388-9398. [CrossRef]

110. Te Loo, D.M.W.; Hagleitner, M.M.; Coenen, M.J. Is there a role for the MTHFR 677C $>$ T and 1298A $>$ C polymorphisms in methotrexate-induced liver toxicity? Pharmacogenomics 2014, 15, 1401-1403. [CrossRef]

111. Hagleitner, M.M.; Coenen, M.J.; Aplenc, R.; Patino-Garcia, A.; Chiusolo, P.; Gemmati, D.; De Mattei, M.; Ongaro, A.; Krajinovic, M.; Hoogerbrugge, P.M.; et al. The role of the MTHFR 677C $>$ T polymorphism in methotrexate-induced liver toxicity: A meta-analysis in patients with cancer. Pharmacogn. J. 2014, 14, 115-119. [CrossRef]

112. Dogan, M.; Karabulut, H.G.; Tukun, A.; Demirkazik, A.; Utkan, G.; Yalcin, B.; Dincol, D.; Akbulut, H.; Icli, F. Relationship between antimetabolite toxicity and pharmacogenetics in Turkish cancer patients. Asian Pac. J. Cancer Prev. 2012, 13, 1553-1556. [CrossRef]

113. Muller, J.; Kralovanszky, J.; Adleff, V.; Pap, E.; Nemeth, K.; Komlosi, V.; Kovacs, G. Toxic encephalopathy and delayed MTX clearance after high-dose methotrexate therapy in a child homozygous for the MTHFR C677T polymorphism. Anticancer Res. 2008, 28, 3051-3054.

114. Park, J.A.; Shin, H.Y. Influence of genetic polymorphisms in the folate pathway on toxicity after high-dose methotrexate treatment in pediatric osteosarcoma. Blood Res. 2016, 51, 50-57. [CrossRef] [PubMed]

115. Blanco, J.G.; Sun, C.L.; Landier, W.; Chen, L.; Esparza-Duran, D.; Leisenring, W.; Mays, A.; Friedman, D.L.; Ginsberg, J.P.; Hudson, M.M.; et al. Anthracycline-related cardiomyopathy after childhood cancer: Role of polymorphisms in carbonyl reductase genes-A report from the Children's Oncology Group. J. Clin. Oncol. 2012, 30, 1415-1421. [CrossRef] [PubMed]

116. Visscher, H.; Ross, C.J.; Rassekh, S.R.; Barhdadi, A.; Dube, M.P.; Al-Saloos, H.; Sandor, G.S.; Caron, H.N.; van Dalen, E.C.; Kremer, L.C.; et al. Pharmacogenomic prediction of anthracycline-induced cardiotoxicity in children. J. Clin. Oncol. 2012, 30, 1422-1428. [CrossRef] [PubMed] 
117. Visscher, H.; Ross, C.J.; Rassekh, S.R.; Sandor, G.S.; Caron, H.N.; van Dalen, E.C.; Kremer, L.C.; van der Pal, H.J.; Rogers, P.C.; Rieder, M.J.; et al. Validation of variants in SLC28A3 and UGT1A6 as genetic markers predictive of anthracycline-induced cardiotoxicity in children. Pediatr. Blood Cancer 2013, 60, 1375-1381. [CrossRef] [PubMed]

118. Wang, X.; Liu, W.; Sun, C.L.; Armenian, S.H.; Hakonarson, H.; Hageman, L.; Ding, Y.; Landier, W.; Blanco, J.G.; Chen, L.; et al. Hyaluronan synthase 3 variant and anthracycline-related cardiomyopathy: A report from the children's oncology group. J. Clin. Oncol. 2014, 32, 647-653. [CrossRef]

119. Visscher, H.; Rassekh, S.R.; Sandor, G.S.; Caron, H.N.; van Dalen, E.C.; Kremer, L.C.; van der Pal, H.J.; Rogers, P.C.; Rieder, M.J.; Carleton, B.C.; et al. Genetic variants in SLC22A17 and SLC22A7 are associated with anthracycline-induced cardiotoxicity in children. Pharmacogenomics 2015, 16, 1065-1076. [CrossRef]

120. Aminkeng, F.; Bhavsar, A.P.; Visscher, H.; Rassekh, S.R.; Li, Y.; Lee, J.W.; Brunham, L.R.; Caron, H.N.; van Dalen, E.C.; Kremer, L.C.; et al. A coding variant in RARG confers susceptibility to anthracycline-induced cardiotoxicity in childhood cancer. Nat. Genet. 2015, 47, 1079-1084. [CrossRef]

121. Singh, P.; Wang, X.; Hageman, L.; Chen, Y.; Magdy, T.; Landier, W.; Ginsberg, J.P.; Neglia, J.P.; Sklar, C.A.; Castellino, S.M.; et al. Association of GSTM1 null variant with anthracycline-related cardiomyopathy after childhood cancer-A Children's Oncology Group ALTE03N1 report. Cancer 2020. [CrossRef]

122. Riedemann, L.; Lanvers, C.; Deuster, D.; Peters, U.; Boos, J.; Jurgens, H.; am Zehnhoff-Dinnesen, A. Megalin genetic polymorphisms and individual sensitivity to the ototoxic effect of cisplatin. Pharmacogn. J. 2008, 8, 23-28. [CrossRef]

123. Ross, C.J.; Katzov-Eckert, H.; Dube, M.P.; Brooks, B.; Rassekh, S.R.; Barhdadi, A.; Feroz-Zada, Y.; Visscher, H.; Brown, A.M.; Rieder, M.J.; et al. Genetic variants in TPMT and COMT are associated with hearing loss in children receiving cisplatin chemotherapy. Nat. Genet. 2009, 41, 1345-1349. [CrossRef] [PubMed]

124. Lanvers-Kaminsky, C.; Sprowl, J.A.; Malath, I.; Deuster, D.; Eveslage, M.; Schlatter, E.; Mathijssen, R.H.; Boos, J.; Jurgens, H.; Am Zehnhoff-Dinnesen, A.G.; et al. Human OCT2 variant c.808G>T confers protection effect against cisplatin-induced ototoxicity. Pharmacogenomics 2015, 16, 323-332. [CrossRef] [PubMed]

125. Pussegoda, K.; Ross, C.J.; Visscher, H.; Yazdanpanah, M.; Brooks, B.; Rassekh, S.R.; Zada, Y.F.; Dube, M.P.; Carleton, B.C.; Hayden, M.R. Replication of TPMT and ABCC3 genetic variants highly associated with cisplatin-induced hearing loss in children. Clin. Pharmacol. Ther. 2013, 94, 243-251. [CrossRef] [PubMed]

126. Hagleitner, M.M.; Coenen, M.J.; Patino-Garcia, A.; de Bont, E.S.; Gonzalez-Neira, A.; Vos, H.I.; van Leeuwen, F.N.; Gelderblom, H.; Hoogerbrugge, P.M.; Guchelaar, H.J.; et al. Influence of genetic variants in TPMT and COMT associated with cisplatin induced hearing loss in patients with cancer: Two new cohorts and a meta-analysis reveal significant heterogeneity between cohorts. PLoS ONE 2014, 9, e115869. [CrossRef]

127. Xu, H.; Robinson, G.W.; Huang, J.; Lim, J.Y.; Zhang, H.; Bass, J.K.; Broniscer, A.; Chintagumpala, M.; Bartels, U.; Gururangan, S.; et al. Common variants in ACYP2 influence susceptibility to cisplatin-induced hearing loss. Nat. Genet. 2015, 47, 263-266. [CrossRef]

128. Vos, H.I.; Guchelaar, H.J.; Gelderblom, H.; de Bont, E.S.; Kremer, L.C.; Naber, A.M.; Hakobjan, M.H.; van der Graaf, W.T.; Coenen, M.J.; te Loo, D.M. Replication of a genetic variant in ACYP2 associated with cisplatin-induced hearing loss in patients with osteosarcoma. Pharm. Genom. 2016, 26, 243-247. [CrossRef]

129. Peters, U.; Preisler-Adams, S.; Hebeisen, A.; Hahn, M.; Seifert, E.; Lanvers, C.; Heinecke, A.; Horst, J.; Jurgens, H.; Lamprecht-Dinnesen, A. Glutathione S-transferase genetic polymorphisms and individual sensitivity to the ototoxic effect of cisplatin. Anticancer Drugs 2000, 11, 639-643. [CrossRef] [PubMed]

130. Spracklen, T.F.; Whitehorn, H.; Vorster, A.A.; Ramma, L.; Dalvie, S.; Ramesar, R.S. Genetic variation in Otos is associated with cisplatin-induced ototoxicity. Pharmacogenomics 2014, 15, 1667-1676. [CrossRef] [PubMed]

131. Manolio, T.A.; Rowley, R.; Williams, M.S.; Roden, D.; Ginsburg, G.S.; Bult, C.; Chisholm, R.L.; Deverka, P.A.; McLeod, H.L.; Mensah, G.A.; et al. Opportunities, resources, and techniques for implementing genomics in clinical care. Lancet 2019, 394, 511-520. [CrossRef]

132. Bilbao-Aldaiturriaga, N.; Gutierrez-Camino, A.; Martin-Guerrero, I.; Pombar-Gomez, M.; Zalacain-Diez, M.; Patino-Garcia, A.; Lopez-Lopez, E.; Garcia-Orad, A. Polymorphisms in miRNA processing genes and their role in osteosarcoma risk. Pediatr. Blood Cancer 2015, 62, 766-769. [CrossRef]

133. Izadpanah, S.; Shabani, P.; Aghebati-Maleki, A.; Baghbani, E.; Baghbanzadeh, A.; Fotouhi, A.; Bakhshinejad, B.; Aghebati-Maleki, L.; Baradaran, B. Insights into the roles of miRNAs; miR-193 as one of small molecular silencer in osteosarcoma therapy. Biomed. Pharmacother. 2019, 111, 873-881. [CrossRef] [PubMed] 
134. Wang, C.; Jing, J.; Cheng, L. Emerging roles of non-coding RNAs in the pathogenesis, diagnosis and prognosis of osteosarcoma. Investig. New Drugs 2018, 36, 1116-1132. [CrossRef] [PubMed]

135. Zhang, Y.; Li, J.; Wang, Y.; Jing, J. The Roles of Circular RNAs in Osteosarcoma. Med. Sci. Monit. 2019, 25, 6378-6382. [CrossRef] [PubMed]

136. Shi, Z.W.; Wang, J.L.; Zhao, N.; Guan, Y.; He, W. Single nucleotide polymorphism of hsa-miR-124a affects risk and prognosis of osteosarcoma. Cancer Biomark. 2016, 17, 249-257. [CrossRef]

137. Bofill-De Ros, X.; Yang, A.; Gu, S. IsomiRs: Expanding the miRNA repression toolbox beyond the seed. Biochim. Biophys. Acta Gene Regul. Mech. 2020, 1863, 194373. [CrossRef] [PubMed]

138. Rainusso, N.; Cleveland, H.; Hernandez, J.A.; Quintanilla, N.M.; Hicks, J.; Vasudevan, S.; Marco, R.A.W.; Allen-Rhoades, W.; Wang, L.L.; Yustein, J.T. Generation of patient-derived tumor xenografts from percutaneous tumor biopsies in children with bone sarcomas. Pediatr. Blood Cancer 2019, 66, e27579. [CrossRef]

139. Stewart, E.; Federico, S.M.; Chen, X.; Shelat, A.A.; Bradley, C.; Gordon, B.; Karlstrom, A.; Twarog, N.R.; Clay, M.R.; Bahrami, A.; et al. Orthotopic patient-derived xenografts of paediatric solid tumours. Nature 2017, 549, 96-100. [CrossRef]

140. Nanni, P.; Landuzzi, L.; Manara, M.C.; Righi, A.; Nicoletti, G.; Cristalli, C.; Pasello, M.; Parra, A.; Carrabotta, M.; Ferracin, M.; et al. Bone sarcoma patient-derived xenografts are faithful and stable preclinical models for molecular and therapeutic investigations. Sci. Rep. 2019, 9, 12174. [CrossRef]

141. Sayles, L.C.; Breese, M.R.; Koehne, A.L.; Leung, S.G.; Lee, A.G.; Liu, H.Y.; Spillinger, A.; Shah, A.T.; Tanasa, B.; Straessler, K.; et al. Genome-Informed Targeted Therapy for Osteosarcoma. Cancer Discov. 2019, 9, 46-63. [CrossRef]

142. Chen, X.; Bahrami, A.; Pappo, A.; Easton, J.; Dalton, J.; Hedlund, E.; Ellison, D.; Shurtleff, S.; Wu, G.; Wei, L.; et al. Recurrent somatic structural variations contribute to tumorigenesis in pediatric osteosarcoma. Cell Rep. 2014, 7, 104-112. [CrossRef]

143. Ambati, S.R.; Shieh, J.H.; Pera, B.; Lopes, E.C.; Chaudhry, A.; Wong, E.W.; Saxena, A.; Su, T.L.; Moore, M.A. BO-1055, a novel DNA cross-linking agent with remarkable low myelotoxicity shows potent activity in sarcoma models. Oncotarget 2016, 7, 43062-43075. [CrossRef] [PubMed]

144. Manara, M.C.; Valente, S.; Cristalli, C.; Nicoletti, G.; Landuzzi, L.; Zwergel, C.; Mazzone, R.; Stazi, G.; Arimondo, P.B.; Pasello, M.; et al. A Quinoline-Based DNA Methyltransferase Inhibitor as a Possible Adjuvant in Osteosarcoma Therapy. Mol. Cancer Ther. 2018, 17, 1881-1892. [CrossRef]

145. Xian, M.; Cao, H.; Cao, J.; Shao, X.; Zhu, D.; Zhang, N.; Huang, P.; Li, W.; Yang, B.; Ying, M.; et al. Bortezomib sensitizes human osteosarcoma cells to adriamycin-induced apoptosis through ROS-dependent activation of p-eIF2alpha/ATF4/CHOP axis. Int. J. Cancer 2017, 141, 1029-1041. [CrossRef] [PubMed]

146. De Luca, A.; Raimondi, L.; Salamanna, F.; Carina, V.; Costa, V.; Bellavia, D.; Alessandro, R.; Fini, M.; Giavaresi, G. Relevance of 3d culture systems to study osteosarcoma environment. J. Exp. Clin. Cancer Res. 2018, 37, 2. [CrossRef] [PubMed]

147. Le Nail, L.R.; Brennan, M.; Rosset, P.; Deschaseaux, F.; Piloquet, P.; Pichon, O.; Le Caignec, C.; Crenn, V.; Layrolle, P.; Herault, O.; et al. Comparison of Tumor- and Bone Marrow-Derived Mesenchymal Stromal/Stem Cells from Patients with High-Grade Osteosarcoma. Int. J. Mol. Sci. 2018, 19, 707. [CrossRef] [PubMed]

148. Bhuvaneshwar, K.; Harris, M.; Gusev, Y.; Madhavan, S.; Iyer, R.; Vilboux, T.; Deeken, J.; Yang, E.; Shankar, S. Genome sequencing analysis of blood cells identifies germline haplotypes strongly associated with drug resistance in osteosarcoma patients. BMC Cancer 2019, 19, 357. [CrossRef]

149. Johnson, J.A.; Bootman, J.L. Drug-related morbidity and mortality. A cost-of-illness model. Arch. Intern. Med. 1995, 155, 1949-1956. [CrossRef]

150. Lazarou, J.; Pomeranz, B.H.; Corey, P.N. Incidence of adverse drug reactions in hospitalized patients: A meta-analysis of prospective studies. JAMA 1998, 279, 1200-1205. [CrossRef]

151. Landrigan, C.P.; Parry, G.J.; Bones, C.B.; Hackbarth, A.D.; Goldmann, D.A.; Sharek, P.J. Temporal trends in rates of patient harm resulting from medical care. N. Engl. J. Med. 2010, 363, 2124-2134. [CrossRef]

152. Trusheim, M.R.; Berndt, E.R.; Douglas, F.L. Stratified medicine: Strategic and economic implications of combining drugs and clinical biomarkers. Nat. Rev. Drug Discov. 2007, 6, 287-293. [CrossRef]

153. Garbayo, E.; Pascual-Gil, S.; Rodriguez-Nogales, C.; Saludas, L.; Estella-Hermoso de Mendoza, A.; Blanco-Prieto, M.J. Nanomedicine and drug delivery systems in cancer and regenerative medicine. Wiley Interdiscip. Rev. Nanomed. Nanobiotechnol. 2020. [CrossRef] 
154. Pereira-Silva, M.; Alvarez-Lorenzo, C.; Concheiro, A.; Santos, A.C.; Veiga, F.; Figueiras, A. Nanomedicine in osteosarcoma therapy: Micelleplexes for delivery of nucleic acids and drugs toward osteosarcoma-targeted therapies. Eur. J. Pharm. Biopharm. 2020, 148, 88-106. [CrossRef]

155. Manolio, T.A.; Abramowicz, M.; Al-Mulla, F.; Anderson, W.; Balling, R.; Berger, A.C.; Bleyl, S.; Chakravarti, A.; Chantratita, W.; Chisholm, R.L.; et al. Global implementation of genomic medicine: We are not alone. Sci. Transl. Med. 2015, 7, 290. [CrossRef] [PubMed]

156. Individualized Therapy for Relapsed Malignancies in Childhood (INFORM). Available online: https: //www.kitz-heidelberg.de/en/for-physicians/clinical-studies/molecular-diagnostics-studies/inform/ (accessed on 30 March 2020).

157. Worst, B.C.; van Tilburg, C.M.; Balasubramanian, G.P.; Fiesel, P.; Witt, R.; Freitag, A.; Boudalil, M.; Previti, C.; Wolf, S.; Schmidt, S.; et al. Next-generation personalised medicine for high-risk paediatric cancer patients-The INFORM pilot study. Eur. J. Cancer 2016, 65, 91-101. [CrossRef] [PubMed]

158. UK 100,000 Genomes Cancer Project. Available online: https://www.genomicsengland.co.uk/about-genomicsengland/the-100000-genomes-project/ (accessed on 30 March 2020).

159. Turnbull, C.; Scott, R.H.; Thomas, E.; Jones, L.; Murugaesu, N.; Pretty, F.B.; Halai, D.; Baple, E.; Craig, C.; Hamblin, A.; et al. The 100000 Genomes Project: Bringing whole genome sequencing to the NHS. BMJ 2018, 361, k1687. [CrossRef]

160. Geisinger MyCode Community Health Initiative. Available online: https://www.geisinger.org/mycode (accessed on 30 March 2020).

161. Ginsburg, G.S.; Phillips, K.A. Precision Medicine: From Science to Value. Health Aff. (Millwood) 2018, 37, 694-701. [CrossRef] [PubMed]

162. Manolio, T.A.; Chisholm, R.L.; Ozenberger, B.; Roden, D.M.; Williams, M.S.; Wilson, R.; Bick, D.; Bottinger, E.P.; Brilliant, M.H.; Eng, C.; et al. Implementing genomic medicine in the clinic: The future is here. Genet. Med. 2013, 15, 258-267. [CrossRef]

163. Owusu Obeng, A.; Fei, K.; Levy, K.D.; Elsey, A.R.; Pollin, T.I.; Ramirez, A.H.; Weitzel, K.W.; Horowitz, C.R. Physician-Reported Benefits and Barriers to Clinical Implementation of Genomic Medicine: A Multi-Site IGNITE-Network Survey. J. Pers. Med. 2018, 8, 24. [CrossRef]

164. Hay, M.A.; Severson, E.A.; Miller, V.A.; Liebner, D.A.; Vergilio, J.; Millis, S.Z.; Chen, J.L. Identifying Opportunities and Challenges for Patients With Sarcoma as a Result of Comprehensive Genomic Profiling of Sarcoma Specimens. JCO Precis. Oncol. 2020, 4, 176-182. [CrossRef]

165. Li, Z.; Dou, P.; Liu, T.; He, S. Application of Long Noncoding RNAs in Osteosarcoma: Biomarkers and Therapeutic Targets. Cell Physiol. Biochem. 2017, 42, 1407-1419. [CrossRef]

166. Khan, F.A.; Pandupuspitasari, N.S.; Huang, C.-J.; Ao, Z.; Jamal, M.; Zohaib, A.; Hakim, M.R.; Zhao, S. CRISPR/Cas9 therapeutics: A cure for cancer and other genetic diseases. Oncotarget 2016, 7, 52541-52552. [CrossRef] [PubMed]

167. Zewde, M.; Kiyotani, K.; Park, J.H.; Fang, H.; Yap, K.L.; Yew, P.Y.; Alachkar, H.; Kato, T.; Mai, T.H.; Ikeda, Y.; et al. The era of immunogenomics/immunopharmacogenomics. J. Hum. Genet. 2018, 63, 865-875. [CrossRef] [PubMed]

168. Le, D.T.; Durham, J.N.; Smith, K.N.; Wang, H.; Bartlett, B.R.; Aulakh, L.K.; Lu, S.; Kemberling, H.; Wilt, C.; Luber, B.S.; et al. Mismatch repair deficiency predicts response of solid tumors to PD-1 blockade. Science 2017, 357, 409-413. [CrossRef] [PubMed]

169. Rizvi, N.A.; Hellmann, M.D.; Snyder, A.; Kvistborg, P.; Makarov, V.; Havel, J.J.; Lee, W.; Yuan, J.; Wong, P.; Ho, T.S.; et al. Cancer immunology. Mutational landscape determines sensitivity to PD-1 blockade in non-small cell lung cancer. Science 2015, 348, 124-128. [CrossRef]

170. Schumacher, T.N.; Scheper, W.; Kvistborg, P. Cancer Neoantigens. Annu. Rev. Immunol. 2019, 37, 173-200. [CrossRef]

171. Chalmers, Z.R.; Connelly, C.F.; Fabrizio, D.; Gay, L.; Ali, S.M.; Ennis, R.; Schrock, A.; Campbell, B.; Shlien, A.; Chmielecki, J.; et al. Analysis of 100,000 human cancer genomes reveals the landscape of tumor mutational burden. Genome Med. 2017, 9, 34. [CrossRef]

172. Chang, T.C.; Carter, R.A.; Li, Y.; Wang, H.; Edmonson, M.N.; Chen, X.; Arnold, P.; Geiger, T.L.; Wu, G.; Peng, J.; et al. The neoepitope landscape in pediatric cancers. Genome Med. 2017, 9, 78. [CrossRef] 
173. Weinstein, J.N.; Collisson, E.A.; Mills, G.B.; Shaw, K.R.; Ozenberger, B.A.; Ellrott, K.; Shmulevich, I.; Sander, C.; Stuart, J.M. The Cancer Genome Atlas Pan-Cancer analysis project. Nat. Genet. 2013, 45, 1113-1120. [CrossRef]

174. Hudson, T.J.; Anderson, W.; Artez, A.; Barker, A.D.; Bell, C.; Bernabe, R.R.; Bhan, M.K.; Calvo, F.; Eerola, I.; Gerhard, D.S.; et al. International network of cancer genome projects. Nature 2010, 464, 993-998.

(C) 2020 by the authors. Licensee MDPI, Basel, Switzerland. This article is an open access article distributed under the terms and conditions of the Creative Commons Attribution (CC BY) license (http://creativecommons.org/licenses/by/4.0/). 